\title{
Alcoholic cardiomyopathy: A review of literature on clinical status and meta-analysis of diagnostic and clinical management methods
}

\author{
Aref Albakri* \\ St-Marien hospital Bonn Venusberg, Department of internal medicine, Bonn, Germany
}

\begin{abstract}
The Center for Disease Control and Prevention (CDC), based on the Alcohol-Related Disease Impact (ARDI) tool, approximates 79,000 deaths annually due to excessive alcohol use. The rates of excessive alcohol use in young adults including college students at the most productive phase of life accounts for a third of lifestyle related cause of death after tobacco use and improper diet/sedentary lifestyle. A significant part of alcohol related deaths are attributable to cardiac death, a condition clinically referred to as alcoholic cardiomyopathy (ACM). The present study seeks to combine current research findings to advance knowledge of alcoholic cardiomyopathy with a view of improving diagnosis and clinical management. The review focusses on clinical description, manifestations, risk factors, pathophysiology, etiology diagnosis and clinical management of ACM.
\end{abstract}

\section{Introduction}

Cardiomyopathy is a severe disorder of the heart muscle characterized by significant functional and/or electrical dysfunction of the myocardium. The most devastating complication is progressive heart failure with considerable morbidity and mortality [1]. Cardiomyopathies can be classified as either primary or secondary. Primary cardiomyopathies are genetic in nature while secondary cardiomyopathies occur in the setting of a medical condition or due to environmental factors such as toxins or medications [1]. Despite definitional variations in research studies, a common clinicopathologic definition of alcoholic cardiomyopathy is a heart muscle condition with a demonstrable cause (e.g. alcohol) or association (e.g. alcoholism) [2]. Alcoholic cardiomyopathy (ACM) is a typical example of secondary cardiomyopathy associated with chronic and excessive consumption of alcohol [3].

Alcohol is one of toxic substances frequently consumed globally [3]. Although daily intake of low to moderate amounts of alcohol improves the cardiovascular health of ischemic and non-ischemic patients $[4,5]$, chronic and excessive consumption of alcohol could result into progressive cardiac dysfunction and heart failure (HF) [5]. Chronic alcohol consumption or abuse is defined as the daily intake of more than $80 \mathrm{~g}$ of alcohol for a period of at least five years [6]. This degree of exposure to alcohol results in reduced contractility of cardiomyocytes, ventricular dilation, fibrosis, and ultimately $\mathrm{HF}$ [7]. Excessive consumption of alcohol is the primary cause of ACM and ACM related HF. With a prevalence of more than 23 million cases globally, HF is a major public health issue [8]. Accounting for approximately $3.8 \%$ of all the reported cases of cardiomyopathy and $21-36 \%$ of all the reported cases of non-ischemic dilated cardiomyopathy, ACM is a major contributor to the rising epidemic of HF [7]. ACM potentially leads to increased left ventricular mass, ventricular dilation, wall thinning, and ventricular dysfunction [7]. ACM patients may also exhibit symptoms of arrhythmias and electrocardiographic abnormalities [9].
Currently, both the European Society of Cardiology (ESC) and the American Heart Association (AHA) consider ACM as a distinct clinical entity [10]. The ESC classifies ACM as an acquired form of dilated cardiomyopathy (DCM). The diagnosis of ACM is often one of exclusion of DCM patients with a long history of chronic and excessive consumption of alcohol [3]. Most studies report a daily consumption of more than $80 \mathrm{~g}$ of alcohol for at least five consecutive years is the threshold for establishing a diagnosis of ACM [6,11-14]. However, the current definition of ACM - chronic and excessive exposure to more than $80 \mathrm{~g} /$ day of alcohol for at least five years - lacks sufficient epidemiological or experimental evidence [3].

Despite existing clinical evidence on the significance of ACM as a major contributor to HF, there is limited clinical data on ACM and the pathophysiologic mechanisms of alcohol on cardiac function. Thus, the current review seeks to develop an in-depth understanding of ACM, in terms of the current paradigm on its epidemiology, clinical manifestation, prognosis, risk factors, pathophysiology, etiology, differential diagnosis and clinical management including meta-analysis of diagnostic and clinical management approaches. Ultimately, the review provides a mechanistic paradigm for future research in the domain of ACM.

\section{Epidemiology}

Epidemiology entails studying and analyzing incidence, distribution, causes, health effects, and possible control mechanisms for disease conditions in defined populations [15]. Epidemiologic

${ }^{*}$ Correspondence to: Aref Albakri, St-Marien hospital Bonn Venusberg, Department of internal medicine, Bonn, Germany, E-mail: arefalbakri@yahoo.com

Key words: cardiomyopathy, CDC, DCM

Received: September 10, 2018; Accepted: September 20, 2018; Published: September 25, 2018 
studies play a critical role in shaping policy decisions and evidencebased practice in public healthcare through the identification of risk factors for disease conditions and prevention targets [16]. A number of experimental and epidemiologic studies have attempted to investigate the epidemiologic characteristics of ACM with a focus on causes, clinical manifestations, prevalence, distribution, as well as possible control mechanisms. However, these studies lack sufficient clinical data to support their conclusions [3].

The mostly advanced, yet contested argument regarding the causation of ACM has been that chronic alcohol abuse is the principal cause of ACM $[3,4,17,18]$. The direct causal linkage between chronic alcohol abuse and the development of ACM remains a controversial subject in cardiology. One school of thought posits that alcohol can cause ACM $[10,19]$ and another that alcohol is merely a trigger for ACM [20-22]. Clinical evidence linking chronic alcohol abuse and the development of ACM is drawn from a range of epidemiological and experimental studies.

Epidemiological studies investigating the nexus between chronic alcohol abuse and development of ACM report a reciprocal relationship between chronic alcohol abuse and ACM. In a case-controlled study evaluating the relationship between alcohol consumption and idiopathic DCM, a correlation was demonstrated between patients diagnosed with DCM and a history of alcohol consumption. The incidence of excessive alcohol abuse among the 100 DCM patients was $40 \%$ compared to $23 \%$ in a control group of 211 healthy individuals [23]. However, the main study limitation was it adopted alcohol consumption threshold of 30$40 \mathrm{~g}$ per day, which is below the recommended threshold of $>80 \mathrm{~g} /$ day. Komajda et al [24] multicenter case-controlled study found that DCM patients admitted as a consequent of HF reported high levels of alcohol consumption $(101 \mathrm{~mL} /$ day $)$ compared to those admitted for surgical procedures ( $64 \mathrm{~mL} /$ day). A study by Gillet et al [25] revealed patients diagnosed with DCM had a higher average alcohol consumption of 82 g per day for 34 years compared to the control group with $30 \mathrm{~g}$ per day for 22 years. The finding was consistent with that of Fernandez-Sola et al. [26] reporting a higher prevalence of DCM among alcoholics than non-alcoholics.

Several other studies investigating the prevalence of ACM in idiopathic dilated cardiomyopathy (IDCM) patients report higher levels of alcohol consumption ranging from 3.8 to $47 \%$ in DCM patients [11$14,23,27]$. A clinical review of $673 \mathrm{HF}$ patients admitted to a hospital in Maryland in the U.S. obtained a 3.8\% prevalence rate of ACM among the DCM patients based on alcohol consumption threshold of $200 \mathrm{~g}$ per day for over 6 months [27]. However, the finding not consistent with several studies conducted in Europe adopting alcohol consumption threshold of $80 \mathrm{~g}$ per day for at least five years [11-14]. These studies report a prevalence of between $23 \%$ and $47 \%$. Figure 1 shows the prevalence of ACM among IDCM patients reported by [11-14,23].

Two other studies reported prevalence rates of DCM based on gender $[10,19]$. The prevalence in female alcoholics was $0.43 \%$ [10] compared to $0.25 \%$ in males [19]. The studies report the effect of alcohol on the functionality of the human heart is dependent on the amount of alcohol the heart is exposed. Gender-based variations in the prevalence of ACM could be due to a lower BMI in women compared to men [3] and a lower alcohol intake among women alcoholics could lead to pathologic effect on cardiac function compared to men. Gender differences in prevalence of ACM is due to greater proportion of body water in men and the larger proportion of body fat in women [28]. Women are also have a slower distribution of alcohol from the blood and possess lower amounts of alcohol mobilizing enzymes such as aldehyde dehydrogenases $[29,30]$. These factors may explain why women may develop ACM earlier, and at a lower lifetime exposure to alcohol (about 40\% dose of alcohol) compared to their men [30].

\section{Clinical manifestation}

Early reports of clinical manifestations of ACM established by Otto von Bollinger, a German pathologist, indicated structural abnormalities such as left ventricular dilation and hypertrophy, and co-morbidities such as delirium tremens and cirrhosis of the liver [3]. Other clinical manifestations reported by William McKenzie include accelerated heart pulse, swelling and enlargement of the veins, poor prognosis with progressive HF, dilated cavities of the heart, and fatty degeneration of the ventricular walls [31]. Other clinical studies have also reported HF as a manifestation of ACM [32-34].

Having coined the expression "Munich beer heart" to demonstrate the effect of chronic alcohol abuse on the human heart in the mid$19^{\text {th }}$ century, Bollinger became the first to highlight the clinical manifestations of ACM. After performing 1,500 autopsies in Munich, Germany, Germany, Bollinger found that deceased individuals, who had been frequenting beer joints in Munich, and consuming 6-12 L of beer per day, presented co-morbidities such as delirium tremens and cirrhosis of the liver [3]. According to Bollinger, the Munich beer heart was associated with fibrosis, fatty degeneration, and hypertrophy [18]. These clinical characteristics are manifest in Figure 2.

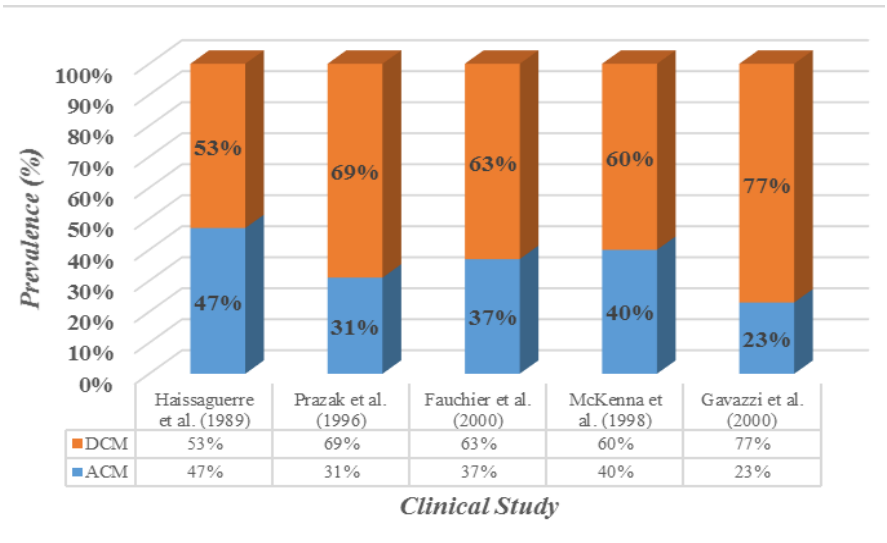

Figure 1. The Prevalence of ACM among IDCM Patients Adapted from Guzzo-Merello et al. 2014 [3]

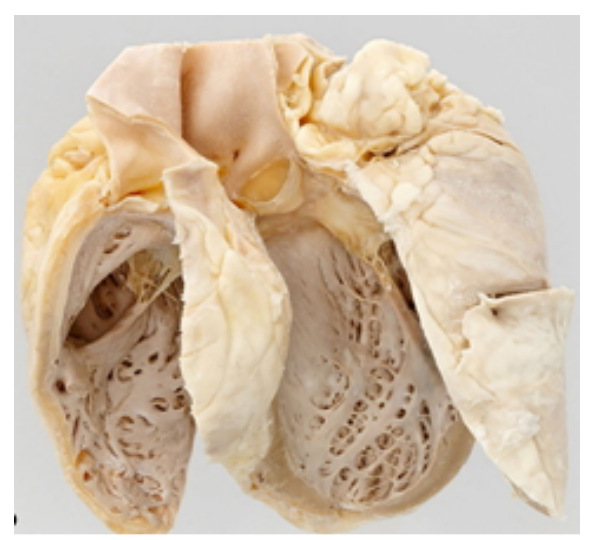

Figure 2. The Munich Beer Heart

The Munich beer heart was the first description of alcoholic cardiomyopathy. The heart reveals significant fibrosis and fatty degeneration and hypertrophy. Adapted from Maisch (2016) [18] 
In a 1902 investigation of arterial and venous pulse and heart movements, William McKenzie found that individuals with a history of chronic alcohol abuse were characterized by accelerated heart pulse and swelling, and engorgement of the veins. These individuals exhibited poor prognosis with progressive HF, and also exhibited fatty degeneration of the ventricular walls and dilated cavities of the heart [31]. Individuals with a history of chronic alcohol abuse may present with diastolic or systolic dysfunction, and may exhibit no preclinical and asymptomatic symptoms or symptomatic ACM, in terms of signs and symptoms of HF [17]. HF symptoms among alcoholics with a longer duration of alcohol consumption have been reported $[35,36]$.

\section{Prognosis}

Chronic alcohol abuse has an adverse toxic effect on vital organs. The toxicity has the potential of damaging and weakening the myocardium over a given period of time [37]. The effect is reduced ability to pump blood efficiently and effectively leading to the expansion of the heart to accommodate extra blood as a compensatory mechanism [37]. Consequently, the heart becomes thinned and enlarged, and eventually the heart muscle and blood vessels stop to function normally as a consequent of the damage and strain [37].

ACM has also been described as a clinical diagnosis exhibited by patients with a history of chronic alcohol abuse suggesting people with a history of chronic alcohol abuse are more likely to be diagnosed with ACM [38]. A consumption of more than $80 \mathrm{~g}$ of alcohol for at least 5 consecutive years amounts to chronic alcohol abuse, and considered the threshold for establishing a diagnosis of ACM [6,11-14]. Chronic alcohol abuse can also have adverse effects on the cardiovascular system, and can lead to conditions such as arrhythmia (including atrial fibrillation, atrial flutter), stroke, hypertension, as well as sudden death [38]. ACM is not only caused by chronic abuse to alcohol but also alcohol withdrawal, which is often associated with stress-induced DCM or takotsubo. Nevertheless, light-moderate alcohol consumption (1-2 drinks per day or 3-9 drinks per week) can help in minimizing the likelihood of cardiac events such as myocardial infarction [38].

The need for complete alcohol withdrawal remains a controversial subject in the ACM literature [3] but some studies report an association between alcohol withdrawal and a reduction in the risk of ACM [38]. After dividing a cohort of 57 ACM patients into two sub-groups based on the evolution of the patients' symptoms during follow-ups, the subgroup comprising a majority of non-drinkers (73\%) reported an improvement in symptoms compared to the sub-group with fewer non-drinkers (25\%), whose symptoms did not improve [39]. The study established that the conditions of patients in the subgroup with fewer non-drinkers (17\%) worsened [37]. However, even in the subgroup with the greatest clinical improvement, patients still exhibited a short-term improvement and ACM [39]. In another study involving nine ACM patients who had fully refrained from consuming alcohol, exhibited a significant improvement in their ejection fraction compared to their counterparts who had not refrained from drinking alcohol. A moderate consumer included in the study registered an improvement in his ejection fraction [40].

In two separate long-term prognosis studies [41,42]; the evolution of ACM patients was compared to the degree of alcohol withdrawal. Both studies found a correlation between a reduction in alcohol consumption or refrain from alcohol drinking and higher rates of patient survival without a heart transplant. Transplant-free survival of DCM patients had become better after 47 months of follow-up than that of their counterparts diagnosed with ACM over the same period of follow-up [41]. However, no significant differences exists between the DCM group and the alcoholics who refrained from consuming alcohol or significantly minimized their alcohol intake [42]. After 7 years of follow-up, transplant-free survival rates in ACM patients, who did refrain from drinking alcohol was worse than their counterparts who refrained from consuming alcohol (27\% for ACM patients who continued drinking alcohol against $45 \%$ for ACM patients who refrained) [41].

In another study investigating the effect of alcohol withdrawal on the myocardium using antimyosin antibodies labelled with Indium-111, included $56 \mathrm{ACM}$ patients (28 of the included patients were former consumers of alcohol, while the other 28 had continued to consume alcohol during the study [43]. The study found that $75 \%$ of the patients who did not refrain from drinking alcohol recorded high absorption levels of Indium-111 compared to only $32 \%$ of the patients who had refrained from drinking alcohol. The foregoing studies thus demonstrate the beneficial effect of alcohol withdrawal for ACM patients.

Other studies on ACM prognosis reveal low to moderate daily consumption of alcohol can have a beneficial effect of ACM patients $[40,44,45]$. Two studies $[44,45]$ provided the suitability of low to moderate daily alcohol consumption as a predictor of better prognosis for heart failure and ischemic cardiomyopathy, irrespective of coronary disease. Existing echocardiographic data also suggest patients who do not completely withdraw from drinking alcohol (minimize their daily intake) may recover LVEF just as non-alcoholics [3]. Another study [46] examining the evolution of ejection fraction among a cohort of 55 ACM patients in relation to their degree of withdrawal. After classifying the cohort into three groups based on the volume of alcohol consumed during the follow-up period, no difference existed in the first year among no-drinkers and those who had reduced alcohol intake to 20$60 \mathrm{~g} /$ day. The non-drinkers and those who had reduced alcohol intake had registered an improvement of $13 \%$ and $12.2 \%$ respectively. On the other hand, the ACM patients who had continued to chronically abuse alcohol (consuming more than $80 \mathrm{~g} / \mathrm{d}$ ) exhibited an average decline of $3.8 \%$ in their ejection fraction [46].

In conclusion, there is a consensus among researchers on the effectiveness of complete alcohol withdrawal in ACM. The debate as to whether moderate alcohol intake is appropriate for achieving improvement in the prognosis of ACM patients remain inconclusive. There is need for future studies to adopt a stricter classification of nonalcohol consumers and alcohol consumers to help in clarifying whether complete alcohol refrain should be mandatory for ACM patients [3]. Despite this recommendation, it is inferable from the few existing studies that ACM patients should refrain from consuming alcohol, since they are likely to find it difficult to practice low to moderate alcohol intake, given their history of alcohol dependence and chronic abuse [3].

\section{Risk factors}

Reference to risk factors for ACM is construed as attributes, characteristics, or exposures of an individual that increase his/her likelihood of developing the ACM condition. Chronic alcohol abuse can have a toxic effect on most of human organs, including the heart. Clinical evidence suggest that the toxicity of alcohol has a damaging and weakening effect on the human heart muscle over a relative period of time, a phenomenon that hinders the ability of the heart to pump blood efficiently and effectively $[4,9,36]$. Whenever the heart is unable to pump blood efficiently and effectively, it undergoes expansion to 
accommodate extra blood. The heart grows thinner and larger, and ultimately both the heart muscle and blood vessels may stop functioning normally as a consequent of the damage and strain. Chronic alcohol abusers may be at risk of contracting ACM [48]. Heavy, daily alcohol consumption ( $>90$ grams of alcohol per day), for a prolonged period (> 5 years) poses the risk of developing ACM [48].

A study investigating risk factors in ACM found both alcoholic and nonalcoholic cardiomyopathy exhibited similar risk factors, incomplete mitral (IMLC) or low cardiac output acted as the relative specific prognostic factor for ACM [49]. A literature review revealed that prolonged daily intake of $\geq 3$ drinks poses the risk of ACM [50]. The existing evidence suggesting the linkage between chronic alcohol abuses has emanated from six categories of research namely: (i) epidemiological studies; (ii) experimental studies; (iii) echocardiographic/hemodynamic studies; (iv) histological studies; (v) basic research studies; and (vi) analytical studies [3].

\section{Epidemiological studies}

Previous epidemiological studies investigating the relationship between chronic alcohol consumption and the development of DCM have established a reciprocal relationship between the disorders. A case control study conducted reported the existence of a relatively higher prevalence of chronic alcohol abuse among patients diagnosed with DCM than was the case in the general population [23]. In a planned multicenter case-control study to investigate the linkage between DCM and the level of alcohol consumption, most of the patients admitted for HF exhibited higher alcohol consumption levels $(101 \mathrm{~mL} / \mathrm{d})$ than their counterparts admitted for surgical procedures, whose alcohol consumption levels was reported at $64 \mathrm{~mL} / \mathrm{d}(\mathrm{RR}=7.6, \mathrm{P}<0.001)$ [51]. In a similar study, a cohort of 23 DCM patients in the study exhibited higher average daily intake of alcohol $(82 \mathrm{~g} / \mathrm{d})$ than the general population's $(30 \mathrm{~g} / \mathrm{d}$; $\mathrm{P}<0.001)$ with a longer duration of alcohol intake (34 vs. 22 years, $\mathrm{P}<0.001$ ).

McKenna et al. [23] also described an incidence of a 40\% excessive consumption of alcohol in a cohort of 100 DCM patients compared to the $20 \%$ reported in a control group comprising 211 healthy subjects. In their analysis of a population of alcoholics, Fernandez-Sola et al. [26] found that alcoholics exhibited higher prevalence of DCM than the general population but the prevalence varied across gender, with a DCM prevalence of $0.43 \%$ for women and $0.25 \%$ for men. This was higher than the DCM prevalence of $0.03 \%$ for women and $0.05 \%$ for men in the general population.

\section{Experimental studies}

Experimental studies involving administration of controlled alcohol have been undertaken to analyze the effect of excessive alcohol consumption on the cardiac muscle [52,53]. All these experimental studies seem to be adopting similar approaches in performing such analysis, during which a specified amount of alcohol is administered to a cohort of alcoholics or volunteers, and consequently, a number of hemodynamic (and in certain cases echocardiographic) parameters are measured [3]. In an experimental study, a cohort of healthy nonalcoholics exhibited an increase in cardiac output as a consequent of decline in peripheral arterial resistance and in increase in cardiac frequency [52]. However, several studies [53-55] found that a potential decrease in ejection fraction and other systolic function associated parameters occur as the hemodynamic changes take place. However, Kupari [56] disagrees arguing alcohol induces changes in both the preload and post-load conditions, which affects cardiac contractility.
Studies carried out with chronic alcohol abusers and in patients with left ventricular (LV) dysfunction established the depressing effect of alcohol on cardiac contractility [3]. Two studies [57,58] found that in patients with LV dysfunction, alcohol, despite occasioning vasodilatation and increasing the heart rate, did not occasion an increase in heart output, and if it did, then such output was lower compared to the case in healthy non-alcoholics. Another study [57] established that the heartbeat volume of a cohort of chronic alcohol abusers reduced significantly after consuming $81 \mathrm{~g}$ of alcohol. In addition, the study demonstrated the ultimate diastolic pressure increased after the intake of $81 \mathrm{~g}$ of alcohol, an indication of a reduction in the LV contractile reserve in the chronic alcoholics. The study used an after-load test with angiotensin to demonstrate the impairment of contractile capacity among chronic alcohol abusers, which results indicated an increase in the end diastolic pressure to a significant extent among alcoholics. Such increase was attributed to a lower heartbeat volume in the alcoholics than in the non-alcoholics [57].

\section{Hemodynamic studies}

Echocardiographic/hemodynamic studies analyzing the effect of excessive alcohol consumption on the structure and function of myocardial also suggest a link between chronic alcohol abuse and ACM. Several echocardiographic studies have evaluated myocardial impairment related to chronic alcohol abuse by measuring hemodynamic and echocardiographic parameters in individuals commencing alcohol withdrawal programs [3]. A slight increase in the pre-ejection period/LV ejection time ratio (PEP/LVET) suggests an impairment of systolic function [59]. Individuals who consume at least $12 \mathrm{Oz}$ of whisky for a period of 6 years and $60 \mathrm{~g}$ of ethanol daily have a small but insignificant increase in LV mass [60]. Individuals consuming more than $80 \mathrm{~g}$ of alcohol for a period of five years have a modest increase in end-systolic and diastolic LV volumes and hypertrophied posterior wall [61]. However, Urbano-Marquez et al. [62] report a decrease in ejection fraction in 52 chronic alcohol abusers.

\section{Histological studies}

Histopathologic studies have also reported an association between excessive alcohol consumption and ACM. Conventional microscopic analysis of muscle biopsies from individuals beginning excessive alcohol intake reveal no significant changes. However, electron microscopic analysis reveals intracellular swelling, accumulation of lipid and glycogen, structural alterations in the sarcoplasmic reticulum and mitochondria as shown in Figure 3 [63].

Based on histological examination, Ferrans et al. [64] observed subtle cellular changes in more than six deceased patients diagnosed with ACM. The study established varying degrees of fibrosis, intramural blood clots, patchy regions of endocardial firbroelastosis, as well as focal collection of swollen cells in the endocardium and the epicardium. As illustrated in Figure 3, swollen mitochondria were observed, presence of edema, with crest alterations and intra-mitochondrial inclusion, indicating occurrence of degenerative processes. Despite these changes, the structural changes are not specific, they qualitatively vary from the changes associated with idiopathic DCM and do not allow for the differentiation of the two conditions [3].

\section{Basic research studies}

Basic research studies seeking to identify the mechanism of alcohol-induced damage to the cardiomyocytes have also reported a linkage between excessive alcohol intake and ACM. They have provided a description of pathological mechanisms that could explain the 


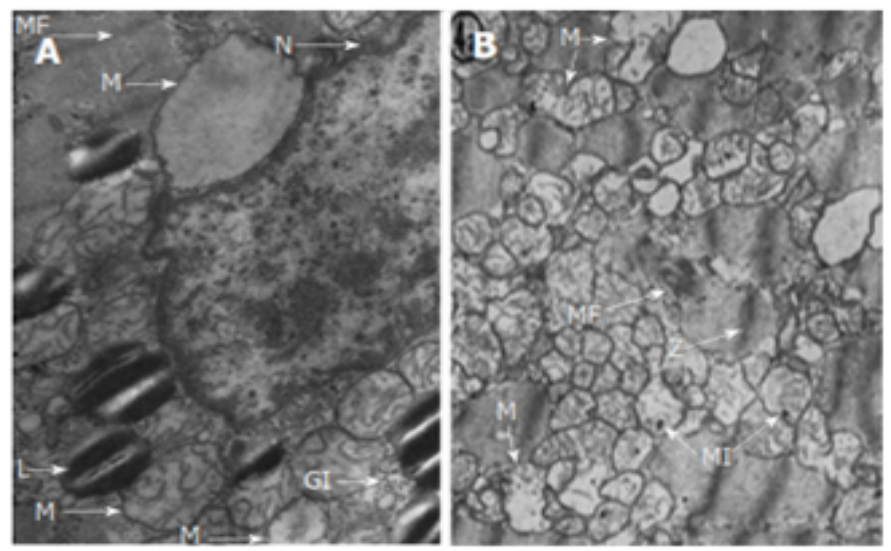

Figure 3. Observable Cellular Changes in ACM

L: Neutral lipids in the form of small cytoplasmic droplets; GI: Glycogen deposits; M: Mitochondria were swollen or edema was present; N: Nucleus; MF: Myofibrils showed a progressively distorted structure (L) Neutral lipid in the form of small cytoplasmic droplets. Adapted from Guzzo-Merello et al. 2014 [3]

functional and structural changes associated with ACM [3]. The origin of such mechanisms may be multifactorial and have a linkage with both the alcohol molecule and acetaldehyde, which is alcohol's main metabolite [3]. Studies on molecular mechanisms provide descriptions of dysfunctions of intracellular organelles that necessitate alterations in the calcium homeostasis and lipid-energetic metabolism, associated with the myofibrils' contractile activity. Despite the numerous existing basic research studies, the sequence of events that characterize the damage of the myocardia due to excessive intake of alcohol remains a highly controversial subject. Whereas some researchers report that the appearance of hypertrophy is the initial event of alcohol-induced myocardial damage, most of the studies reviewed by [3] concur that cardiomyocytes loss characterizes the core event of the alcohol-induced myocardial damage.

\section{Pathophysiology}

Pathophysiology refers to the biological and physical manifestations of the ACM as they correlate with the underlying abnormalities and physiological disturbances. As have been noted in the subsequent sections of this paper, ACM is a specific heart muscle condition, which is common in individuals with a history of prolonged chronic alcohol abuse. Piano and Phillips [17] literature review study finds ACM occasions a range of adverse histological, structural, and cellular changes in the myocardium. They find the main pathological elements of ACM are accelerated protein catabolism, generation of oxidative stress, derangements in fatty acid metabolism and transport, apoptotic cell death, and impaired mitochondrial biogenetics/stress [17].

Three studies [65-67] described apoptosis, defined as the alterations of the excitation-contraction coupling in cardiac myocytes. Other mechanisms described so far are alterations in the structure and function of the mitochondria sarcoplasmic reticulum [63]; alterations in cytosolic calcium flows [68]; induction of ANP and p21 mRNA expression in ventricular myocardium [66]; alterations in the regulation of myosin ATPase [69]; increased oxidative stress [70]. According to [3], the pathophysiology of ACM is determined by mechanisms of a genetic nature.

\section{Generation of oxidative stress}

Existing clinical evidence reports continued and prolonged intake of excessive intake of alcohol leads to the generation of oxidative stress within the myocardium. This can occur directly through the stimulation of the production of free radicals or indirectly through the activation of other systems or hormones like angiotensin II [17]. Oxidative stress may also be involved in the pathophysiology of a range of cardiovascular insults in ACM [72]. Most of the adverse cardiac intracellular effects reported among chronic consumers of alcohol by most investigations tend to exhibit oxidative stress situations [17]. Some of these reported effects include myocyte loss and disarray [72], changes in intracellular $\mathrm{Ca}^{2+}$ handling [73], sarcoplasmic reticulum dysfunction [74, 75, 76], decreased myofibrillar ATPase activity [77], contractile protein fragmentation and disarray $[79,80]$, depressed mitochondrial function $[75,77,78]$, fatty acid accumulation in the intracellular organelles [81], and decreased myofibrillar calcium sensitivity [82].

Previous studies have reported cases of ethanol-induced changes in the oxidative enzyme activity and levels $[82,83]$. There is an increase in catalase activity in the autopsy heart samples obtained from individuals who had been diagnosed with ACM [82]. In a murine study, high myocardial catalase levels and activity were found among ethanol-fed rats compared to the control group. After reviewing various studies on the relationship between oxidative stress and ACM, Piano and Phillips [17] concluded that the findings of these studies provided clinical evidence to suggest that the phenomenon of increased catalase activity among individuals with a prolonged history of excessive alcohol consumption is both an adaptive and protective response to the presence of ethanol in the heart.

\section{Apoptotic cell death}

Apoptosis is a consequence of lipid peroxidation and oxidative stress in most organ systems, including the heart. Myocyte loss or cell death can occasion organ dysfunction and pathology [84]. Apoptotic cell death has been associated to the development of ACM [17]. Two clinical investigations $[85,86]$ found that prolonged and continued consumption of excessive alcohol could lead to apoptotic cell death and consequently leads to the development of ACM. A 1965 histopathological study [87] found myocytes within the hearts of patients diagnosed with ACM had lost their cross-striated appearance and were bearing pyknotic nuclei. Pyknotic nuclei, which is a reduction in the size of the nucleus, is a depiction of apoptosis. In a 2006 study [88], an evaluation of apoptosis in the hearts of individuals who reported to have had a long history of excessive alcohol consumption. The study findings show indicators of apoptosis were significantly prevalent among all the investigated individuals with prolonged and continued consumption of excessive alcohol. A more recent study [89] corroborates the previous reports on the occurrence of apoptosis in individuals with a long history of excessive alcohol consumption.

\section{Impaired mitochondrial bioenergetics/stress}

Evidence of impaired mitochondrial stress is a common phenomenon in most ethanol and heart studies. This is attributed to the clinical observation that mitochondria is a major target for radical injury [17]. Dysfunctional mitochondria are not only associated with the generation of more reactive oxygen species (ROS) and are bioenergetically less efficient but also likely to initiate apoptosis. Additionally, mitochondrial DNA is more prone to oxidative stress due to its close proximity to ROS generation as well as its lack of DNA repair mechanisms as opposed to nuclear DNA [90].

A previous studies involving evaluation of myocardial biopsies from alcoholics have reported evidence of mitochondrial enlargement and disorganization, as well as cristae degeneration, all which suggest mitochondrial dysfunction [91]. An analysis of autopsy samples from 
patients diagnosed with ACM established evidence of mitochondrial swellings (2-3 times the normal mitochondrial size). The swollen mitochondria lacked cristae, while others had cristae, which were deformed [87]. Analysis of autopsy samples from ACM patients also suggest atrophy of myofibrils, increased population of mitochondria, dilation of the sarcoplasmic reticulum, increased number of lysosome like structures, as well as mitochondriosis [82].

\section{Derangements in fatty acid metabolism and transport}

A number of alcohol-induced pathologies such as cirrhosis and hepatic steatosis have exhibited aberrations in fatty acid metabolism and uptake. The formation of fatty ethyl esters (FAEE) has also been established in ethanol-induced cell injury. The FAEE are esterification products of ethanol and fatty acids [17]. A significant increase in the content of FAEE in post mortem myocardium samples of victims of chronic alcohol abuse has also been demonstrated [92]. The concentration of FAEE ranged from $17 \mu \mathrm{m}$ to $115 \mu \mathrm{m}$, with the lowest levels being established in those victims with a reported history of chronic alcohol abuse $(19 \mu \mathrm{m}$ and $28 \mu \mathrm{m})$ [17]. An attachment of FAEE to mitochondria has a disruptive effect on mitochondrial function, a phenomenon that explains the adverse effect of excessive alcohol consumption on mitochondrial function [17]. An increase in FAEE content and potential variations in the enzyme FAEE synthase can act as a mechanism for the development of ACM [93]. A study involving a cohort of 39 chronic alcohol abusers, reported high plasma FAEE concentrations in all the 39 alcohol abusers, established a correlation between plasma FAEE and blood alcohol concentration (BAC), and reported chronic alcohol abusers with a $\mathrm{BAC}<300 \mathrm{mg} \%$ exhibited relatively higher plasma FAEE concentrations [94].

Overall, these findings propose an association between alcohol consumption and a dose-dependent increase in long-chain fatty acid (LCFA) uptake, accumulation of triglyceride, and de novo synthesis. The accumulation of triglyceride has been found to correspond to a decrease in the content levels of myocardial adenosine triphosphate (ATP) as well as a decrease in myocardial contractility [17].

\section{Etiology}

The term etiology has been defined as the study of the causes of diseases, with a view to gaining guiding insights on therapeutic management [95]. The etiology of ACM is largely associated with generation of oxidative stress, apoptotic cell death, impaired mitochondrial stress/bioenergetics, derangements in fatty acid metabolism and transport, as well as accelerated protein catabolism. In a more recent review of the etiology of ACM, the interrelated cellular process of apoptosis, oxidative stress, and mitochondrial metabolism have been identified as the putative mechanisms that promote the development of ACM [96]. Mitochondrial function, assessed by respiratory chain and membrane potential function, is adversely affected by alcohol. Alcohol adversely affect indicators of oxidative stress such as superoxide dismutase, malondialdehyde, and glutathione metabolites. However, the effect of alcohol on the indicators of oxidative stress is sex-dependent. In addition, there is a linkage between alcohol-induced oxidative stress and apoptosis, a phenomenon that demonstrates the codependence and interrelatedness of the oxidative stress and apoptosis in ACM [96].

\section{Diagnosis}

The lack of pothognomic features available distinguishing ACM from other underlying causes of myocardial dysfunction and heart failure imposes a challenge to confirmatory diagnosis of ACM. The frequent existence of other risk factors associated with cardiomyopathy further complicates ACM diagnosis. However, patient history plays a critical role in the diagnosis ACM since it facilitates the exclusion of other potential etiologies such as cocaine use, anthracycline drugs and ischemic heart diseases [29]. Table 1 provides a summary and description of the clinical signs and symptoms, and their role in the diagnosis of ACM.

ACM clinically manifests by demonstrating four-chamber dilation, normal or decreased LV wall thickness, as well as low cardiac output. Clinical stigmata of HF such as cardiomegaly with or without rales, as well as elevated jugular venous pulse may be evident in ACM patients, mostly in decompensated states [29]. The cause of death in ACM patients resemble the cause of death in patients with progressive chronic HF, idiopathic cardiomyopathy, and sudden cardiac death $[13,29]$. A worse diagnosis is associated with alcoholics with cirrhosis and simultaneous cardiomyopathy [99].

Hypertrophic cardiomyopathy is characterized by thickened cardiac muscles, which limits the size of cardiac chamber $[100,101]$. Restrictive cardiomyopathy on the other hand is commonly caused by sarcoidosis, amyloidosis, and hemochromatosis [100]. Arrhythmogenic right ventricular cardiomyopathy on the other hand is an autosomal dominant condition, which is clinically manifested through syncope, symptoms of HF, ventricular arrhythmias, and sudden death [100]. The differential diagnosis of ACM excludes other causes of DCM. Whereas diagnosis of ACM is generally made clinically in patients with a reported history of prolonged chronic abuse of alcohol, consideration needs to be given to other potential causes in a study involved a cohort of seven patients with a history of alcoholism [102]. The results of endomyocardial biopsy established hemochromatosis in two of the patients, a patient with amyloidosis and doxorubicin-related toxicity in each case, and alcoholic heart disease in three of the patients [109].

\section{Meta-analysis of diagnostic methods}

\section{Search strategy}

Literature-based meta-analysis was conducted to combine findings from research studies on diagnosis of ACM. Studies were searched from online databases: PubMed, Medline and EMBASE as well as in non-indexed databases such as Google Scholar. Broad-based search terms including "diagnosis of Alcoholic cardiomyopathy", "diagnosis",

Table 1. Clinical Signs and Symptoms

\begin{tabular}{|l|l|}
\hline Signs/Symptoms & Description \\
\hline Asymptomatic & $\begin{array}{l}\text { Most individuals with ACM tend to be symptomatic during } \\
\text { the early stages of the condition [97] }\end{array}$ \\
\hline $\begin{array}{l}\text { Both [97] and [98] contend that ACM can occur secondary } \\
\text { abuse }\end{array}$ & $\begin{array}{l}\text { to chronic alcohol abuse. According to [97] and [98] } \\
\text { dilated cardiomyopathy (DCM) is due to thiamin and other } \\
\text { vitamin deficiencies as a consequent of alcoholism. }\end{array}$ \\
\hline Dyspnea [97] & $\begin{array}{l}\text { Patients with ACM develop dyspnea as a consequent of } \\
\text { congestive cardiac failure as well as pulmonary edema. In } \\
\text { most cases, ACM patients develop dyspnea with exertion. } \\
\text { In cases of severe HF, ACM patients may be dyspneic even } \\
\text { when they are resting. }\end{array}$ \\
\hline Orthopnea [97] & $\begin{array}{l}\text { While lying down, patients of ACM can complain of } \\
\text { dyspnea. Episodes of cough frothy sputum and dyspnea } \\
\text { may also be experienced by patients, especially at night. } \\
\text { According to [97], all these symptoms are occasioned by } \\
\text { HF and pulmonary edema. }\end{array}$ \\
\hline Peripheral edema & $\begin{array}{l}\text { The development of peripheral edema is occasioned by HF. } \\
\text { The presence of cirrhosis in some patients may exacerbate } \\
\text { the development of peripheral edema [97]. }\end{array}$ \\
\hline Sudden cardiac death & \begin{tabular}{l} 
ACM patients can present with sudden cardiac death [97]. \\
\hline
\end{tabular}
\end{tabular}


Table 2. A Summary of Results on Meta-Analysis of Diagnostic Methods

\begin{tabular}{|c|c|c|c|c|c|}
\hline Author (year) & Sample Size & Diagnostic Method & Diagnostic Feature & Clinical Procedure & Findings \\
\hline $\begin{array}{l}\text { Wilke et al. (1998) } \\
{[103]}\end{array}$ & $\begin{array}{l}20 \text { males diagnosed } \\
\text { with ACM and } 30 \\
\text { males diagnosed with } \\
\text { idiopathic DCM }\end{array}$ & $\begin{array}{l}\text { Carbohydrate- } \\
\text { deficient transferrin } \\
\text { (CDT) }\end{array}$ & $\begin{array}{l}\text { CDT scrum } \\
\text { concentrations }\end{array}$ & $\begin{array}{l}\text { The CDT scrum concentrations } \\
\text { analyzed through a modified } \\
\text { radioimmunoassay test in the samples, } \\
\text { and results compared with reported } \\
\text { alcohol consumption. }\end{array}$ & $\begin{array}{l}\text { The CDT is a more sensitive and specific marker than } \\
\text { other makers such as gamma-glutamyltransferase } \\
\text { (GGT) and mean corpuscular hemoglobin (MCV). In } \\
\text { addition, CDT is a maker of alcoholic intake, which } \\
\text { helps in differentiating between ACM and IDCM. }\end{array}$ \\
\hline $\begin{array}{l}\text { Cohen \& Kaplan } \\
(1979)[104]\end{array}$ & 271 & SGOT/SGPT ratio & $\begin{array}{l}\text { Elevation of SGOT/ } \\
\text { SGPT (values }>40 \\
\text { Karmen units) }\end{array}$ & $\begin{array}{l}\text { Analysis of SGOT/SGPT ratio levels } \\
\text { using the Karmen method. }\end{array}$ & $\begin{array}{l}\text { Patients with ACM have a significantly elevated } \\
\text { SGOT/SGPT ratio }(2.85+/-0.2)\end{array}$ \\
\hline $\begin{array}{l}\text { Williams \& } \\
\text { Hoofnagle (1988). } \\
{[105]}\end{array}$ & 177 patients & AST/ALT ratio & $\begin{array}{l}\text { ratio of the serum } \\
\text { aspartate to alanine } \\
\text { amino-transferase } \\
\text { levels (AST/ALT) }\end{array}$ & $\begin{array}{l}\text { Analysis of the AST/ALT ratio in the } \\
177 \text { sampled patients. }\end{array}$ & $\begin{array}{l}\text { An AST/ALT ratio of }<1.0 \text { suggests the presence } \\
\text { of ACM. }\end{array}$ \\
\hline $\begin{array}{l}\text { Xiao et al. (2014) } \\
{[107]}\end{array}$ & $\begin{array}{l}\text { A } 48 \text {-year old male } \\
\text { with ACM, and a } \\
\text { history of intake of } \\
\text { inferior liquor }(500- \\
750 \mathrm{~g} / \mathrm{d}) \text { for over } 30 \\
\text { years. }\end{array}$ & $\begin{array}{l}\text { Heart MRI-3T and } \\
\text { 2D-heart ultrasound }\end{array}$ & & $\begin{array}{l}\text { An examination of 2D-heart ultrasound } \\
\text { and heart MRI-3T performed for the } \\
\text { patient. A similar procedure carried out } \\
\text { for the patient's brother, and results } \\
\text { comparatively analyzed. }\end{array}$ & $\begin{array}{l}\text { Heart MRI-3T and 2D-heart ultrasound provides } \\
\text { the basis of ACM, and helps to differentiate ACM } \\
\text { from other non-ischemic cardiomyopathy such } \\
\text { as restrictive cardiomyopathy and hypertrophic } \\
\text { cardiomyopathy. }\end{array}$ \\
\hline $\begin{array}{l}\text { Madhubala, } \\
\text { Subhashree, \& } \\
\text { Shanthi (2013) } \\
{[108]}\end{array}$ & 25 male alcoholics. & CTD; MCV; GGT & $\begin{array}{l}\text { Serum Carbohydrate } \\
\text { Deficient Transferrin }\end{array}$ & $\begin{array}{l}\text { Percentage of Serum CDT assessed } \\
\text { using immuno Turbidimetric assay, } \\
\text { ELISA method (iMark, Bio-Rad } \\
\text { Laboratories,). }\end{array}$ & $\begin{array}{l}\text { The \% CDT exhibited the highest sensitivity ( } 84 \%) \\
\& \text { specificity ( } 92 \% \text { ) compared to MCV's }(48 \% \\
\text { and } 52 \% \text { ) and GGT's ( } 64 \% \text { and } 72 \%) \text {. The results } \\
\text { suggest that \% CDT is more sensitive biomarker for } \\
\text { diagnosing ACM than MCV and GGT. }\end{array}$ \\
\hline $\begin{array}{l}\text { Bell et al. (1996) } \\
{[109]}\end{array}$ & $\begin{array}{l}502 \text { consecutive } \\
\text { patients admitted } \\
\text { at Aker University } \\
\text { Hospital }\end{array}$ & $\begin{array}{l}\text { CDTect and AXIS } \\
\% \text { CDT }\end{array}$ & $\begin{array}{l}\text { Serum Carbohydrate } \\
\text { Deficient Transferrin }\end{array}$ & $\begin{array}{l}\text { CDT examined using CDTect and two } \\
\text { versions of AXIS \% CDT (AX CDT } 1 \\
\text { and AX CDT 2) }\end{array}$ & $\begin{array}{l}\text { The sensitivity for detecting alcohol consumption of } \\
\geq 50 \mathrm{~g} / \mathrm{d} \text { was found to be } 69 \% \text { for CDTect; } 65 \% \text { for } \\
\text { AX CDT } 1 \text {; and } 50 \% \text { for AX CDT } 2 \text {. }\end{array}$ \\
\hline $\begin{array}{l}\text { Walter et al. } \\
(2001)[110]\end{array}$ & $\begin{array}{l}148 \text { alcohol- } \\
\text { dependent patients. }\end{array}$ & $\begin{array}{l}\% \mathrm{CDT} \text { of total } \\
\text { transferrin) }(\% \mathrm{CDT}) \\
\text { method. }\end{array}$ & $\begin{array}{l}\text { \%CDT levels; liver } \\
\text { enzyme concentrations }\end{array}$ & $\begin{array}{l}\text { \%CDT levels of sampled patients } \\
\text { determined before and after a } \\
\text { subsequent period of abstinence. }\end{array}$ & $\begin{array}{l}\text { A cluster analysis generated three clusters: Cluster } \\
1 \text { (GGT, AST, \& ALT); cluster } 2 \text { (MCV levels and } \\
\text { Munich Alcoholism Test [MALT] results); and } \\
\text { cluster } 3 \text { (CDT measurement variants). The three } \\
\text { clusters measure varying detriments to patients and } \\
\text { existing CDT variants are commensurate. }\end{array}$ \\
\hline $\begin{array}{l}\text { Mundle et al. } \\
(2000)[111]\end{array}$ & $\begin{array}{l}177 \text { male alcohol- } \\
\text { dependent patients }\end{array}$ & $\begin{array}{l}\text { CDT, GGT, \& MCV } \\
\text { markers }\end{array}$ & $\begin{array}{l}\text { Serum CDT; serum } \\
\text { GGT; \& MCV volume }\end{array}$ & $\begin{array}{l}\text { Patients' blood test before and after a } \\
\text { period of abstinence to determine the } \\
\text { sensitivity of the markers. }\end{array}$ & $\begin{array}{l}\text { Sensitivity of makers among patients had abstained } \\
\text { for more than } 4 \text { days (GGT, } 33 \% \text {; CDT, } 14 \% \text {; MCV, } \\
42 \% \text { ). Sensitivity of markers among patients who } \\
\text { had abstained for } \leq 4 \text { days (GGT, } 72 \% \text {; CDT, } 56 \% \text {; } \\
\text { MCV, } 48 \% \text { ). GGT proved more sensitive than CDT } \\
\text { and MCV at P }<0.05 \text { and P }<0.001 \text { respectively. A } \\
\text { combination of CDT and GGT was characterized } \\
\text { by sensitivity }>90 \% \text {. Both CDT and GGT are not } \\
\text { affected by age. MCV increases significantly and } \\
\text { lineally with age. }\end{array}$ \\
\hline $\begin{array}{l}\text { Hock et al. (2005) } \\
{[112]}\end{array}$ & $\begin{array}{l}101 \text { alcohol- } \\
\text { dependent patients }\end{array}$ & $\begin{array}{l}\% \mathrm{CDT} \text {; GGT; and } \\
\text { MCV biomarkers. }\end{array}$ & $\begin{array}{l}\text { Serum CDT; serum } \\
\text { GGT; \& MCV volume }\end{array}$ & $\begin{array}{l}\text { A modified automated assay used to } \\
\text { determine \%CDT. }\end{array}$ & $\begin{array}{l}\text { \%CDT marker provides a high diagnostic value for } \\
\text { supporting diagnosis of ACM. The specificity of } \\
\% \text { CDT is superior to GGT and MCV biomarkers. }\end{array}$ \\
\hline $\begin{array}{l}\text { Rublo et al. (1997) } \\
{[113]}\end{array}$ & 179 males & CDT marker & $\begin{array}{l}\text { Serum levels of CDT } \\
\text { compared with those } \\
\text { of MCV, ALT, AST, } \\
\text { and GGT }\end{array}$ & $\begin{array}{l}\text { Serum levels of CDT and those of } \\
\text { MCV, ALT, AST, and GGT measured. }\end{array}$ & $\begin{array}{l}\text { CDT is a more effective laboratory test for detecting } \\
\text { alcohol abuse than GGT, MCV, ALT, and AST. }\end{array}$ \\
\hline $\begin{array}{l}\text { Madhubala, } \\
\text { Subhashree, \& } \\
\text { Shanthi (2013) } \\
{[114]}\end{array}$ & 25 male alcoholics & CDT marker & $\begin{array}{l}\text { Liver function test } \\
\text { (Serum Bilirubin), } \\
\text { AST, ALT, Alkaline } \\
\text { Phosphatase (ALP), } \\
\text { GGT, MCV and blood } \\
\text { glucose level. }\end{array}$ & $\begin{array}{l}\text { Serum Bilirubin, AST, ALT, Alkaline } \\
\text { Phosphatase (ALP), GGT, and blood } \\
\text { glucose level tests done using an } \\
\text { automated biochemistry analyzer, } \\
\text { XL-300, while MCV done using an } \\
\text { automated hematology analyzer Sysmex } \\
\text { KX-21 }\end{array}$ & $\& \mathrm{CDT}$ is a more sensitive biomarker \\
\hline $\begin{array}{l}\text { Yamada et al. } \\
(2013)[115]\end{array}$ & $\begin{array}{l}184 \text { Japanese habitual } \\
\text { drinkers }\end{array}$ & $\begin{array}{l}\text { The Nephelometric } \\
\text { N Latex CDT Assay }\end{array}$ & Serum CDT & $\begin{array}{l}\text { Diagnostic performance of the direct } \\
\text { immunoassay for } \% \mathrm{CDT}(\mathrm{N} \text { Latex } \\
\mathrm{CDT} \text { ) assessed in the subjects. }\end{array}$ & $\begin{array}{l}\text { The positive rates of } \% \text { CDT and GGT in heavy } \\
\text { drinkers was } 58.3 \% \text { and } 41.7 \% \text { respectively. A } \\
\text { combination of } \% \text { CDT and GGT yielded a sensitivity } \\
\text { and specificity of } 75 \% \text { and } 95 \% \text { respectively. The } \\
\text { conclusion was that the } \% \text { CDT determined using } \\
\text { automated N Latex CDT could be an effective } \\
\text { complementary biomarker to GGT in detecting } \\
\text { ACM. }\end{array}$ \\
\hline $\begin{array}{l}\text { Yersin et al. (1995) } \\
{[116]}\end{array}$ & $\begin{array}{l}1202 \text { consecutive } \\
\text { patients }\end{array}$ & $\begin{array}{l}\text { CDT, GGT, \& MCV } \\
\text { Biomarkers }\end{array}$ & $\begin{array}{l}\text { Serum levels of CDT, } \\
\text { GGT, and MCV. }\end{array}$ & $\begin{array}{l}\text { Determination of serum levels of CDT, } \\
\text { GGT, and MCV in the sampled patients. } \\
\text { Operating characteristics of CDT, GGT, } \\
\text { and MCV determined in accordance } \\
\text { with alcohol consumption and CAGE- } \\
\text { questionnaire test. }\end{array}$ & $\begin{array}{l}\text { Elevated levels of CDT observed in } 21 \% \text { of men } \\
\text { and } 7 \% \text { of women. The sensitivity and specificity of } \\
\text { the tests were CDT }(0.58,0.82) \text {; GGT }(0.69,0.65) \text {; } \\
\text { and MCV }(0.27,0.91) \text {, leading to the suggestion } \\
\text { that CDT determination can be a useful test for } \\
\text { diagnosing ACM. }\end{array}$ \\
\hline
\end{tabular}




\begin{tabular}{|c|c|c|c|c|c|}
\hline $\begin{array}{l}\text { Aithal et al. (1998) } \\
\text { [117] }\end{array}$ & $\begin{array}{l}81 \text { consecutive } \\
\text { patients ( } 42 \text { male, } 39 \\
\text { female) aged 20-85 } \\
\text { years }\end{array}$ & CDTect, Pharmacia & $\begin{array}{l}\text { Serum levels of CDT, } \\
\text { GGT, and MCV. }\end{array}$ & $\begin{array}{l}\text { Participants subjected to conventional } \\
\text { blood tests, including MCV and GGT. } \\
\text { CDT level estimated using an enzyme } \\
\text { immunoassay (CDTect, Pharmacia). }\end{array}$ & $\begin{array}{l}\text { The sensitivity, specificity and positive predictive } \\
\text { value for elevated serum CDT were } 69 \%, 81 \% \text {, } \\
\text { and } 41 \% \text { respectively. The positive predictive } \\
\text { value for elevated serum GGT and elevated } \\
\text { erythrocyte MCV were } 43 \% \text { and } 41 \% \text { respectively. } \\
\text { In conclusion, conventional biomarkers (serum GGT } \\
\text { and erythrocyte MCV) can be effective diagnostic } \\
\text { methods in outpatients with a wide range of alcohol } \\
\text { consumption. Serum CDT when combined with } \\
\text { serum GGT and erythrocyte MCV provides an } \\
\text { effective diagnostic method for detecting heavy } \\
\text { drinking. }\end{array}$ \\
\hline $\begin{array}{l}\text { Allen et al. (2000) } \\
\text { [118] }\end{array}$ & 124 female samples & $\begin{array}{l}\text { CDT, GGT, and } \\
\text { MCV Biomarkers. }\end{array}$ & $\begin{array}{l}\text { Serum CDT, serum } \\
\text { GGT, and erythrocyte } \\
\text { MCV }\end{array}$ & $\begin{array}{l}\text { Assessment of Serum CDT, serum } \\
\text { GGT, and erythrocyte MCV levels }\end{array}$ & $\begin{array}{l}\text { The use of a combination of CDT and GGT in } \\
\text { female patients enhances sensitivity, while reducing } \\
\text { specificity. The sensitivity of both CDT and GGT as } \\
\text { biomarkers is improved using MCV. }\end{array}$ \\
\hline
\end{tabular}

CDT: Carbohydrate-Deficient Transferrin; GGT: Gamma-Glutamyltransferase; MCV: Mean Corpuscular Hemoglobin; ALP: Alkaline Phosphatase ALT: Alanine Transaminase; AST: Aspartate AminotransferaseTable 3. Pharmacological Regime for Alcoholism and ACM

"diagnostic methods", and "alcoholic cardiomyopathy". Studies were included if they (a) recruited patients prospectively or retrospectively; (b) recruited adult patients; (c) used at least one diagnostic methods for ACM; (d) described the clinical procedure; and (e) provided outcomes of diagnosis. Titles and abstracts of potential studies were reviewed against the inclusion criteria. Additional studies were identified from screening of review articles and bibliographies of the included studies. There was no restriction on publication language or publication year. Studies with only abstracts with insufficient data, case series (examine few patients) and conference papers were excluded. Each included study was screened and relevant data extracted. The extracted data was recorded in Microsoft Excel Worksheet. Data extracted included first author and publication year, sample size recruited, diagnostic method used, diagnostic feature targeted, clinical procedure and a summary of main findings. Table 2 provides a summary of the data extracted from the included studies (Figure 4).

\section{Study characteristics}

After a hierarchical search strategy (screening titles, abstracts and finally the full paper) against the inclusion criteria, fifteen (15) studies were included in this literature-based meta-analysis [103-105,107-118]. The 15 studies published between 1979 and 2014 recruited a combined population of 3,217 patients with a significant gender bias towards male patients. The main diagnostic methods used were percentage of carbohydrate-deficient transferrin (\%CDT), SGOT/SGPT ratio, AST/ALT ratio, percentage of cardiac MRI, and biomarkers - Mean Corpuscular Hemoglobin (MCV) and Gamma-Glutamyltransferase (GGT). The main diagnostic feature targeted was serum CDT concertation ( $73 \%$ of the studies). The others were the elevation of SGOT/SGPT and serum AST/ALT ratio.

\section{Study outcomes}

Carbohydrate-deficient transferrin (CDT) emerged as the most common biomarker used to identify individuals suffering from cardiomyopathy due to chronic alcohol abuse. The CDT biomarker was investigated in $73 \%$ of the studies compared with other biomarkers such as gamma-glutamyltransferase (GGT) [108,111,116-118] and mean corpuscular hemoglobin (MCV) [108,111,112,116-118] in different environmental conditions, populations, and clinical settings. The present analysis reveals CDT is a useful diagnostic method for chronic alcohol abuse and subsequent cardiac problems. It has a high sensitivity, specificity and positive predictive value of $69 \%, 81 \%$, and $41 \%$ respectively [117]. In addition, CDT achieves a higher sensitivity when used in combination with conventional biomarkers such as GGT, MCV, AST, and ALT. CDT is slightly sensitive than GGT in men,

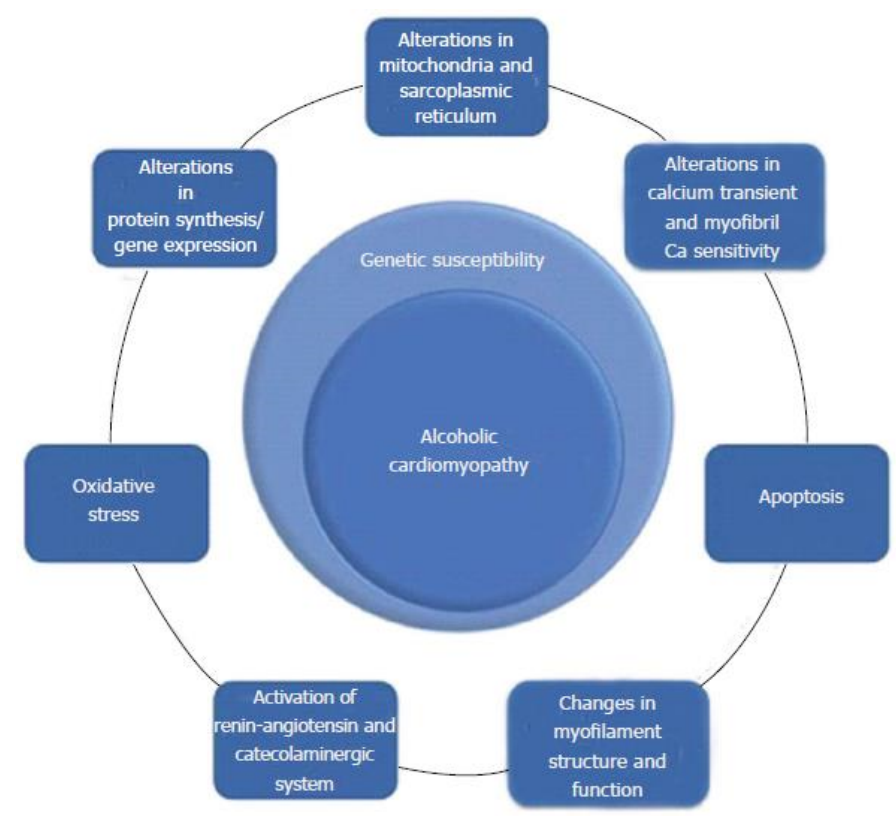

Figure 4. The Pathophysiology of Alcoholic Cardiomyopathy

Common pathophysiologic mechanisms for ACM are oxidative stress, apoptosis, alteration on calcium hemostasis, impaired mitochondrial stress, altered protein synthesis and changes in myofilament structure and function. Adapted from Guzzo-Merello et al. 2014 [3]

implying its appropriateness in determining alcohol abuse in men [106]. Combined with GGT sensitivity goes up to $90 \%$ irrespective of age [111]. However, the analysis also reveals that the specificity of CDT is reduced when used in combination with the conventional laboratory markers such as GGT for instance. On the other hand, the sensitivity of GGT is reportedly higher when used in women

\section{Discussion}

Alcoholic cardiomyopathy lacks pothognomic morphological or functional myocardial features making differential diagnosis from other cardiomyopathies especially dilated cardiomyopathy and other etiologies of heart failure challenging. Its diagnosis is primarily by exclusion of other probable or suspected etiologies. Despite the diagnostic challenges, the present analysis reveals diagnosis of alcoholic cardiomyopathy is complemented using laboratory tests. The cornerstone of laboratory test is the assessment of carbohydratedeficient transferrin (CDT) assessed by $73 \%$ of studies included in the present literature-based meta-analysis. The specificity, sensitivity and accuracy of CDT is supplemented by the assessment of other important 
biomarkers including liver function tests (alanine transaminase (ALT), aspartate aminotransferase (AST), and alkaline phosphatase (ALP). In addition to CDT, the ratio of SGOT/SGPT $(2.85+/-0.2)$ and AST/ALT ratio $<1.0$ strongly suggests the presence of ACM [104,105].

Whereas the value of laboratory tests in the confirmatory diagnosis of ACM are not in dispute, they do not confirm the diagnosis of ACM in the absence of findings from non-invasive cardiac imaging modalities. Laboratory testing are useful to provide complementary diagnostic clues for confirming the presence of ACM. The history of the patient is another key diagnostic procedure valuable for excluding other potential etiologies such as anti-cancer medication or ischemic heart disease strengthening diagnosis. Imaging modalities are the initial diagnostic methods to characterize and detect underlying alcoholinduced myocardial dysfunction. Cardiac functional parameters such as echocardiographic abnormalities including increased left atrial dimension, increased LV wall thickness and decreased fractional shortening precede onset of clinical symptoms in individuals with a history of alcohol abuse, suggest the presence of ACM but are not definitive [29,97]. Other echocardiographic abnormalities are four chamber dilatation, low cardiac output and normal/decreased LV wall thickness [29]. Tests such as electrocardiography abnormalities such as a third heart sound and elevated jugular venous pulse and cardiomegaly with or without rales are common in decompensated state [97].

In summary, ACM presents as a variant of dilated cardiomyopathy, which complicates diagnosis. Although cardiac imaging may demonstrates myocardial abnormalities, laboratory testing of CDT and liver tests such as GGT, MCV, AST and ALT strengthen the diagnosis of ACM. However, diagnostic challenges emerge because of the co-existent of ACM with liver disease due to cirrhosis. In addition, diagnostic challenges may arise from the association of supraventricular arrhythmias with heavy alcohol use (holiday syndrome) and association with sudden cardiac death are complications of chronic alcohol abuse in ACM patients.

\section{Clinical management}

Although alcoholic cardiomyopathy lacks clinical guidelines or specific pharmacotherapies yet ACM patients with chronic alcohol abuse disorder and severe HF are at risk of death due to arrhythmias, depressed heart conduction, as well as systemic or pulmonary embolism.
According to the AHA's current diagnostic and treatment strategies for specific dilated cardiomyopathies, the main clinical management approach to ACM is absolute abstinence from alcohol [106]. With no known effective therapy, other treatment approaches adopt that conventional treatment of heart failure such as pharmacotherapy and device therapy [18].

\section{Alcohol abstinence}

Early and absolute alcohol abstinence could reverse myocardial dysfunction in ACM patients $[119,120]$. An earlier study revealed that prolonged bed rest for several months without alcohol intake is efficacious in the reversal of myocardial dysfunction in ACM patients [120]. Even if depressed LV function does not completely normalize, clinical signs and symptoms of heart failure improve after alcohol abstinence. However, even after alcohol abstinence, the overall prognosis remains ominous with a mortality rate of $40 \%$ to $50 \%$ within three to six years. Still, survival is significantly lower for ACM patients who continue to partake alcohol [106].

\section{Pharmacotherapy}

Pharmacotherapy for ACM adopts medication developed for heart failure. Either used alone or concomitant with alcohol abstinence is an important initial therapeutic approach to ACM. For abstinence maintenance, recommended medication include Acamprosate, Diazepam, Naltrexone, Disulfiram and Nalmefene. For support for HF, common medication are ACE-inhibitors, digitalis, betaclockers, anticoagulants and diuretics. Table 3 provides a summary of pharmacological regimes for ACM and alcoholism.

Medical therapy has beneficial outcomes for ACM patients. Medication such as naltrexone, an opiate receptor antagonist that works by blocking endogenous opioid reward, reduces alcohol-cueconditioned reinforcement signals. Another common medication is Acamprosate, which is an action-exerting agent through excitatory amino acids. ACM can also be treated through an integrated approach that involves both pharmacologic and psychosocial therapy, including self-help groups or Alcoholic Anonymous [18]. The treatment of ACM adopts the usual regimen for HF therapy, including angiotensin converting enzyme (ACE) inhibitors, beta-blockers, diuretics, including eplerinone or spironolactone, as well as digitalis in atrial fibrillation for rate control (Table 3), where deemed appropriate [18].

Table 3. Pharmacological Regime for Alcoholism and ACM

\begin{tabular}{|c|c|c|c|c|c|}
\hline Treatment Purpose & Type of Medication & Treatment Goal & Dosage & Adverse Effect & Evidence of Adverse Effect \\
\hline \multirow{5}{*}{ 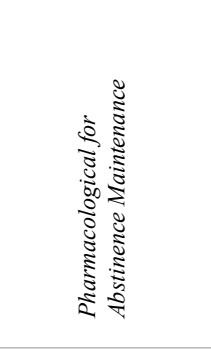 } & Acamprosate & Abstinence & $666 \mathrm{mg} \mathrm{x3/d}$ & $\begin{array}{l}\text { Altered libido, diarrhea, rash, } \\
\text { pruritus }\end{array}$ & High \\
\hline & Diazepam & Delirium avoidance & According to need & Sleepiness, dizziness & Symptomatic \\
\hline & Naltrexone & Abstinence & $\begin{array}{l}50-100 \mathrm{mg} / \text { day } \\
380 \mathrm{mg} \mathrm{i.m} / \mathrm{month}\end{array}$ & $\begin{array}{l}\text { Dizziness, nausea, joint/ } \\
\text { muscle pain, headache }\end{array}$ & High \\
\hline & Disulfiram & Abstinence & $200 \mathrm{mg} /$ day & $\begin{array}{l}\text { Polyneuritis, dizziness, } \\
\text { headache, hepatotoxicity, } \\
\text { rash, importance }\end{array}$ & Mixed, requires supervision \\
\hline & Nalmefene & $\begin{array}{l}\text { Reduction of alcohol intake } \\
\text { or abstinence }\end{array}$ & $18 \mathrm{mg} /$ day & $\begin{array}{l}\text { Vomiting, headache, } \\
\text { dizziness, rash, nausea. }\end{array}$ & Moderate \\
\hline \multirow{5}{*}{ 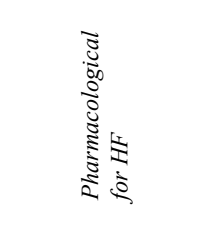 } & ACE inhibitors & $\mathrm{HF}+$ prognosis & Based on tolerance & -- & High in HF \\
\hline & Digitalis & Rate control & In accordance with digoxin & Avoidance of overdose & Moderate in atrial fibrillation \\
\hline & Beta-blockers & $\mathrm{HF}+$ prognosis & Based on tolerance & -- & High in HF \\
\hline & Anticoagulants & Stroke avoidance & INR $1.8-2.2$ in $\mathrm{AF}$ & Bleeding & High in HF \\
\hline & Diuretics & $\mathrm{HF}+$ prognosis & Based on tolerance & - & High in HF \\
\hline
\end{tabular}

Adapted from Maisch, (2016) [18]. 
Table 3 summarizes the treatment of alcoholism and ACM, including the type of medication, its treatment goal, dosage, associated adverse effect, as well as evidence of such effect. Given the challenges of noncompliance, trauma, as well as over dosage associated with ACM clinical management, caution for anticoagulation is often warranted [18].

\section{Implantable cardioverter-defibrillator}

Device therapy using implantable cardioverter-defibrillator (ICD) or cardiac resynchronization therapy (CRT) is a new clinical management method for patients with congestive HF, involving the implantation of a biventricular pacemaker (BVP) for purposes of the simultaneous stimulation of both ventricles [121]. ICD and CRT implantation in ACM follows the same criteria as in DCM [3]. However, given the likelihood for ACM patients to experience a significant recovery of systolic function, the use of ICD in clinical management of ACM becomes challenging [3, 122].

\section{Meta-analysis of acm clinical management}

This meta-analysis sought to combine findings on studies investigating clinical management of alcoholic cardiomyopathy. The intention was to identify the most common treatment options to improve survival rates of individuals suffering from ACM.

\section{Search strategy}

Studies were searched from electronic/online databases: PubMed, EMABSE and Google Scholar, using broad-based search terms such as "pharmacological therapy for ACM", "pharmacological treatment of ACM", "abstinence", and "ICD", or "CRT." Only prospective or retrospective studies that involved ACM clinical management approaches, characterized by a follow-up period of at least six months were included for analysis. The inclusion criteria were studies that (a) were retrospective or prospective; (b) recruited ACM patients; (c) recruited adults patients; (d) included at least one of the following clinical outcomes: clinical management methods, follow-up period and clinical outcomes. Additional studies were retrieved from screening bibliographies of included studies. There was no restriction on publication period or publication language. The abstracts and titles of retrieved studies were reviewed to establish their relevance. Table 4 summarizes data extracted from the included studies.

\section{Study characteristics}

After screening all potential studies from electronic search and additional studies from a review of bibliographies, a total of seven (7) studies published between 1971 and 2017 meeting the inclusion criteria were included in the present meta-analysis. The prolonged study period indicates progressive research-evidence in clinical management of ACM. The studies recruited in total 459 patients all diagnosed with ACM having a mean age of 51 years. The patients were followed up in a mean period of 58 months. The most studied treatment method was alcohol abstinence investigated in $57 \%$ of the studies and medical therapy investigated by $29 \%$ of the studies and finally device therapy studied by $14 \%$ of the studies.

Table 4. A Summary of Data on Studies Investigating Clinical Management of ACM

\begin{tabular}{|c|c|c|c|c|c|c|}
\hline Author(s) [Ref \#] & Year of Study & Sample Size & $\begin{array}{l}\text { Mean Age } \\
\text { (Yrs.) }\end{array}$ & $\begin{array}{l}\text { Clinical Management } \\
\text { Method(s) }\end{array}$ & $\begin{array}{c}\text { Follow-Up Period } \\
\text { (Months) }\end{array}$ & Outcomes \\
\hline La Vecchia et al. [123] & 1996 & 19 & 52.4 & Abstinence & 24 & $\begin{array}{l}-48 \% \text { of patients improved significantly, in terms } \\
\text { of increased LV ejection fraction }(\mathrm{EF}>15 \% \text { from } \\
\text { baseline) }\end{array}$ \\
\hline Nicolas et al. [124] & 2002 & 52 & 48 & Abstinence & 48 & $\begin{array}{l}\text {-Significant improvement in the LVF (EF, } 0.131[95 \% \\
\text { CL, } 0.069-0.193]) \text {. } \\
-10 \text { patients who continued to consume alcohol }(<80 \\
\text { g/d) died during the study. }\end{array}$ \\
\hline Gavazzi et al. [12] & 2000 & 79 & 53 & Abstinence & 120 & Significant improvement in EF \\
\hline Fauchier et al. [125] & 2000 & 50 & 51 & $\begin{array}{l}\text { ACE inhibitors, } \\
\text { Diuretics, } \\
\text { Digoxin, and/or Nitrates. }\end{array}$ & 87 & $\begin{array}{l}\text {-LV EF improved from } 27.0+/-11.0 \% \text { to } 35.4+/- \\
14.6 \% \text { in } 28 \text { patients who abstained }(25 \% \text { of the } 50 \\
\text { patients abstained). } \\
-\mathrm{LV} \mathrm{EF} \mathrm{improved} \mathrm{from} 30.7+/-11.7 \% \text { to } 54.2+/- \\
15.0 \% \text { in patients who did not abstain. }\end{array}$ \\
\hline Duncker et al. [126] & 2017 & 117 & 51 & ICD & 21 & $\begin{array}{l}\text { Patients with newly diagnosed ACM and LVEF } \leq \\
35 \% \text { exhibited elevated risk of ventricular fibrillation, } \\
\text { suggesting that ICD is appropriate for patients with } \\
\text { newly diagnosed ACM with severely reduced LVEF, to } \\
\text { minimize cardiac death. }\end{array}$ \\
\hline $\begin{array}{l}\text { Guzzo-Merello et al } \\
{[127]}\end{array}$ & 2015 & 94 & 49.6 & Beta-blocker therapy & 59 & Recovery in LVF \\
\hline McDonald et al. [128] & 1971 & 48 & 52 & Abstinence & 47 & $\begin{array}{l}\text {-Heart size normalized with bed rest in } 57 \% \text { of the } 37 \\
\text { patients who abstained. } \\
\text {-Only } 10 \% \text { of the } 11 \text { patients who failed to abstain } \\
\text { survived. }\end{array}$ \\
\hline
\end{tabular}

LVEF: Left ventricular function; LV: left ventricular; LVF: left ventricular function 


\section{Study outcomes}

The present findings reveal alcohol abstinence is the mainstay of clinical management of patients with ACM. Alcohol abstinence was associated with significantly improved LV function (LVEF increased by $15 \%$ from baseline) $[12,123,124]$. It was also associated with normalized cardiac size in more than half (57\%) of the patients [128] and significant improvement in mean pulmonary artery pressure $(27.8 \mathrm{mmHg})$ and pulmonary capillary wedge pressure $(18.4 \mathrm{mmHg})$ [123]. On the other hand, the clinical value of alcohol abstinence in the management of ACM was evident in between $10 \%$ and $19 \%$ of ACM patients who continued to consume alcohol died within 48 months [124,128]. Besides alcohol abstinence, medical therapy was the second most common clinical management approach for ACM patients in $29 \%$ of the studies. The common medication were Angiotensin-converting enzyme (ACE) - inhibitors, diuretics, Digoxin, beta-blockers and/or nitrates. The target of medical therapy was treatment of heart failure. Medical therapy was associated with significantly improved LV function (LEVF from $27 \%$ to $35 \%$ in patients who abstained from alcohol and from $31 \%$ to $54 \%$ in patients who did not abstained from alcohol [125,127]. Finally, device therapy using implantable cardioverter-defibrillator (ICD) was the least common method in $29 \%$ of the studies. Device therapy was indicated in patients with severely depressed LV function (LVEF $\leq 35 \%$ ) and at an elevated risk of developing ventricular fibrillation. The clinical intention of ICD was to minimize the risk of cardiac death [126].

\section{Discussion}

The present findings reveal the initial clinical management of patients diagnosed with ACM should be etiologic based [106]. Since the primary etiology of ACM is chronic alcohol intake, the cornerstone of treatment should be total abstinence from alcohol. Abstinence of alcohol improves LV function, and relieves pulmonary artery and pulmonary capillary wedge pressure associated with ACM. The present finding is consistent with AHA practice guidelines recommendation that absolute abstinence from alcohol is the primary and most effective prophylactic and therapeutic approach to management of LV dysfunction and heart failure symptoms in the setting of ACM [106]. The clinical value of absolute abstinence from alcohol in reversing myocardial dysfunction in ACM patients has already been demonstrated in earlier studies $[119,120]$. Moreover, bedrest has been shown to improve the effect of alcohol abstinence in reversing myocardial dysfunction [120]. In some ACM patients, LV dysfunction does not completely resole but there is relief of symptoms of heart failure [106].

The present findings also reveal medical therapy is effective in improving LV function and relieving symptoms of heart failure. These findings is supported by earlier reports indicating that due to the lack of standard therapy, treatment for ACM has adopted medication developed for heart failure. HF mediation such as ACE-inhibitors, beta-blockers, and diuretics have protective effect against progression of heart failure and the normalization of LV dysfunction [18]. Medical therapy is also effective in the treatment of atrial fibrillation and other ventricular arrhythmias, as well as the prevention and management of thrombosis in ACM patients [18]. However, for patients with severely depressed LV function and symptoms of heart failure, device therapy using ICD reveals beneficial long-term outcomes. ICD is usually recommended for newly diagnosed cases of ACM with significantly reduced $L V E F \leq 35 \%$, and at a greater risk of ventricular arrhythmias to reduce the risk of cardiac death. The effectiveness of ICD is further improved by concomitant use with cardiac resynchronization therapy (CRT) to stimulate both ventricles and reduce the risk of arrhythmias as well as to improve LV function [122]. In summary, clinical management of ACM focuses on eliminating causes, normalizing LV function and relieving symptoms of heart failure. The most effective therapy is absolute evidence from alcohol. Medication is also effective in normalizing LV function and relieving HF symptoms. ICD on the other hand is recommended for ACM patients with severely depressed LV function.

\section{Conclusion}

Chronic and excessive alcohol consumption is among the leading causes of lifestyle-related diseases. It is the primary etiology of a myocardial dysfunction clinically referred to as alcoholic cardiomyopathy (ACM). The prevalence of ACM varies significantly across regions ranging between $23 \%$ and $47 \%$ in DCM patients partaking excessive alcohol. Clinically, ACM manifests as increased left ventricular mass, ventricular dilation, ventricular wall thinning and ventricular dysfunction. Patients also exhibit high blood pressure, downregulation of the immune system and progressive heart failure. The condition has an ominous prognosis predicted by the presence of arrhythmias, stroke, hypertension and progressive heart failure. The etiopathogenesis of ACM is not well understood, but hypothesized to be variable and inter-related pathologic mechanisms, mostly involving the generation of oxidative stress, myocyte apoptosis, impaired mitochondrial bioenergetics and dysfunction in fatty acids metabolism and transport. Diagnosis of ACM is by exclusion. It is a two-step diagnosis process beginning with cardiac imaging to characterize myocardial abnormalities. The second step involves laboratory tests involving carbohydrate-deficient transferrin (CDT) tests, liver tests (ALT, AST and ALP) and ECG abnormalities aimed to detect excessive alcohol consumption and to exclude other potential underlying cardiac and systemic disease that may cause myocardial dysfunction. Clinical management of ACM is challenging due to the lack of standard clinical guidelines. However, absolute abstinence from alcohol is the principal treatment option efficacious in relieving symptoms and reversing myocardial damage. For patients with severely depressed LV function and symptomatic heart failure, conventional therapy for heart failure mostly pharmacotherapy and device therapy (ICD) are recommended. Heart transplantation is the last line of treatment recommended for ACM patients with end-stage heart failure or refractory to optimal medical therapy and ICD.

\section{References}

1. Wexler RK, Elton T, Pleister A, Feldman D (2009) Cardiomyopathy: an overview. Am Fam Physician 79: 778-784. [Crossref]

2. Pomerance A (1972) Classification of the secondary cardiomyopathies. The pathologist's view. Postgrad Med J 48: 714-721. [Crossref]

3. Guzzo Merello G, Cobo Marcos M, Gallego Delgado M, Garcia Pavia P (2014) Alcoholic cardiomyopathy. World J Cardiol 6: 771-781.

4. Bryson CL, Mukamal KJ, Mittleman MA, Fried LP, Hirsch CH, et al. (2006) The association of alcohol consumption and incident heart failure: The cardiovascular health study. J Am Coll Cardiol 48: 305-311.

5. Movva R, Figueredo VM (2013) Alcohol and the heart: to abstain or not to abstain? Int J Cardiol 164: 267-276. [Crossref]

6. Jones KW (2005) A Murine Model of alcoholic cardiomyopathy: A role for zinc and metallothionein in fibrosis. Am J Pathol 167: 301-304.

7. Piano MR (2002) Alcoholic cardiomyopathy incidence, clinical characteristics, and pathophysiology. Chest 121: 1638-1650. 
8. Brandt M, Garlapati V, Oelze M, Sotiriou E, Knorr M, et al. (2016) NOX2 amplifies acetaldehyde-mediated cardiomyocyte mitochondrial dysfunction in alcoholic cardiomyopathy. Scientific Reports 14: 1-15.

9. Laonigro I, Correale M, Di Biase M, Altomare E (2009) Alcohol abuse and heart failure. Eur J Heart Fail 11: 453-462. [Crossref]

10. Elliott P, Andersson B, Arbustini E, Bilinska Z, Cecchi F, et al. (2008) Classification of the cardiomyopathies: A position statement from the European Society of Cardiology Working Group on Myocardial and Pericardial Diseases. Eur Heart J 29: 270-276.

11. Haissaguerre M, Fleury B, Gueguen A, Bonnet J, Lorente P, et al. (1989) Mortality of dilated myocardiopathies as a function of continuation of alcohol drinking. Multivariate analysis concerning 236 patients. Presse Med 18: 711-714

12. Gavazzi A, De Maria R, Parolini M, Porcu M (2000) Alcohol abuse and dilated cardiomyopathy in men. Am J Cardiol 85: 1114-1118.

13. Fauchier L, Babuty D, Poret P, Casset Senon D, Autret ML, et al. (2000) Comparison of long-term outcome of alcoholic and idiopathic dilated cardiomyopathy. Euro Heart J 21: 306-314

14. Prazak P, Pfisterer M, Osswald S, Buser P, Burkart F (1996) Differences of disease progression in congestive heart failure due to alcoholic as compared to idiopathic dilated cardiomyopathy. Euro Heart J 17: 251-257.

15. Smith GD (2001) The uses of 'Uses of epidemiology'. Int J Epidemiol 30: 1146-1155. [Crossref]

16. Mrozek Budzyn D (2010) The significance of epidemiological studies for progress of measles elimination. Przegl Epidemiol 64: 361-366.

17. Piano MR, Phillips SA (2014) Alcoholic cardiomyopathy: Pathophysiologic insights. Cardiovasc Toxicol 14: 291-308.

18. Maisch B (2016) Alcoholic cardiomyopathy: The result of dosage and individual predisposition. Herz 41: 484-493. [Crossref]

19. Maron BJ, Towbin JA, Thiene G, Antzelevitch C, Corrado D, et al. (2006) Contemporary definitions and classification of the cardiomyopathies: An American Heart Association Scientific statement from the Council on Clinical Cardiology, Heart Failure and Transplantation Committee; Quality of Care and Outcomes Research and Functional Genomics and Translational Biology Interdisciplinary Working Groups; and Council on Epidemiology and Prevention. Circulation 113: 1807-1816.

20. Movva R, Figueredo VM (2013) Alcohol and the heart: to abstain or not to abstain? Int J Cardiol 164: 267-276. [Crossref]

21. Askanas A, Udoshi M, Sadjadi SA (1980) The heart in chronic alcoholism: a noninvasive study. Am Heart J 99: 9-16. [Crossref]

22. Kino M, Imamitchi H, Morigutchi M, Kawamura K, Takatsu T (1981) Cardiovascular status in asymptomatic alcoholics, with reference to the level of ethanol consumption. Br Heart J 46: 545-551.

23. McKenna CJ, Codd MB, McCann HA, Sugrue DD (1998) Alcohol consumption and idiopathic dilated cardiomyopathy: A case control study. Am Heart J 135: 833-837.

24. Komajda M, Richard JL, Bouhour JB, Sacrez A, Bourdonnec C, et al. (1986) Dilated cardiomyopathy and the level of alcohol consumption: A planned multicentre case control study. Euro Heart J 7: 512-519.

25. Gillet C, Juilliere Y, Pirollet P, Aubin HJ, Thouvenin A, et al. (1992) Alcohol consumption and biological markers for alcoholism in idiopathic dilated cardiomyopathy: A casecontrolled study. Alcohol and Alcoholism 27: 353-358.

26. Fernández Solà J, Estruch R, Nicolás JM, Paré JC, Sacanella E, et al. (1997) Comparison of alcoholic cardiomyopathy in women versus men. Am J Cardiol 80: 481-485.

27. Kasper EK, Agema WR, Hutchins GM, Deckers JW, Hare JM, et al. (1994) The causes of dilated cardiomyopathy: A clinicopathologic review of 673 consecutive patients. $J$ Am Coll Cardiol 23: 586-590.

28. Ely M, Hardy R, Longford NT, Wadsworth MEJ (1999) Gender differences in the relationship between alcohol consumption and drink problems are largely accounted for by body water. Alcohol and Alcoholism 34: 894-902.

29. George A, Figueredo VM (2011) Alcoholic cardiomyopathy: a review. J Card Fail 17: 844-849. [Crossref]

30. Thomasson HR (2002) Gender differences in alcohol metabolism. In: Galanter M, Begleiter H, Deitrich R, Gallant D, Goodwin D, et al. (Eds.,). Recent developments in alcoholism. Springer US 1: 163-179.
31. Mackenzie W (1902) The study of the pulse, arterial, venous, and hepatic, and of the movements of the heart. Am J Med Sci 1: 124-129.

32. Mansourati J, Forneiro I, Genet L, Le Pichon J, Blanc JJ (1990) Regression of dilated cardiomyopathy in a chronic alcoholic patient after abstinence from alcohol. Arch Mal Coeur Vaiss 83: 1849-1852.

33. Mølgaard H, Kristensen BO, Baandrup U (1990) Importance of abstention from alcohol in alcoholic heart disease. Int J Cardiol 26: 373-375.

34. Guillo P, Mansourati J, Maheu B, Etienne Y, Provost K, et al. (1997) Long-term prognosis in patients with alcoholic cardiomyopathy and severe heart failure after total abstinence. Am J Med Sci 79: 1276-1278.

35. Mathews EC, Gardin JM, Henry WL, Del Negro AA, Fletcher RD, et al. (1981) Echocardiographic abnormalities in chronic alcoholics with and without overt congestive heart failure. Am J Cardiol 47: 570-578.

36. Urbano Marquez A, Estruch R, Navarro Lopez F, Grau JM, Mont L, et al. (1989) The effects of alcoholism on skeletal and cardiac muscle. $N$ Engl J Med 320: 409-415. [Crossref]

37. Murrell D (2017) Alcoholic cardiomyopathy and your health. Available at: http://www. healthline.com/health/alcoholism/cardiomyopathy\#overview1 [Accessed August 22, 2017]

38. Popjes ED (2014) Alcoholic cardiomyopathy. Available at: http://emedicine.medscape com/article/152379-overview [Accessed August 22, 2017]

39. Demakis JG, Proskey A, Rahimtoola SH, Jamil M, Sutton GC, et al. (1974) The natural course of alcoholic cardiomyopathy. Ann Intern Med 80: 293-297.

40. Guillo P, Mansourati J, Maheu B, Etienne Y, Provost K, et al. (1997) Long-term prognosis in patients with alcoholic cardiomyopathy and severe heart failure after total abstinence. Am J Cardiol 79: 1276-1278.

41. Gavazzi A, De Maria R, Parolini M, Porcu M (2000) Alcohol abuse and dilated cardiomyopathy in men. Am J Cardiol 85: 1114-1118. [Crossref]

42. Fauchier L, Babuty D, Poret P, Casset Senon D, Autret ML, et al. (2000) Comparison of long-term outcome of alcoholic and idiopathic dilated cardiomyopathy. Eur Heart J 21: 306-314.

43. Ballester M, Martí V, Carrió I, Obrador D, Moya C, et al. (1997) Spectrum of alcoholinduced myocardial damage detected by indium-111-labeled monoclonal antimyosin antibodies. J Am Coll Cardiol 29: 160-167.

44. Bryson CL, Mukamal KJ, Mittleman MA, Fried LP, Hirsch CH, et al. (2006) The association of alcohol consumption and incident heart failure: the Cardiovascular Health Study. Am Coll Cardiol 48: 305-311.

45. Abramson JL, Williams SA, Krumholz HM, Vaccarino V (2001) Moderate alcohol consumption and risk of heart failure among older persons. JAMA 285: 1971-1977. [Crossref]

46. Nicolás JM, Antúnez E, Thomas AP, Fernández Solà J, Tobías E, et al. (1998) Ethanol acutely decreases calcium transients in cultured human myotubes. Alcohol Clin Exp Res 22: 1086-1092.

47. Craig RW, Martin GL, Jane CE, Luc D, Ellison RC, et al. (2002) Alcohol Consumption and Risk for Congestive Heart Failure in the Framingham Heart Study. Available at: https://annals.altmetric.com/details/3203834 [Accessed September 6, 2017]

48. Awtry EH, Philippides GJ (2010) Alcoholic and cocaine-associated cardiomyopathies. Prog Cardiovasc Dis 52: 289-299.

49. Kinney EL, Wright RJ 2nd, Caldwell JW (1989) Risk factors in alcoholic cardiomyopathy. Angiology 40: 270-275. [Crossref]

50. Mukamal KJ (2010) The effects of smoking and drinking on cardiovascular disease and risk factors. Available at: https://pubs.niaaa.nih.gov/publications/arh293/199- 202.htm [Accessed September 18, 2017]

51. Komajda M, Richard JL, Bouhour JB, Sacrez A, Bourdonnec C, et al. (1986) Dilated cardiomyopathy and the level of alcohol consumption: A planned multicentre casecontrol study. Eur Heart J 7: 512-519.

52. Juchems R, Klobe R (1969) Hemodynamic effects of ethyl alcohol in man. Am Heart J78: 133-135. [Crossref]

53. Cameli M, Ballo P, Garzia A, Lisi M, Bocelli A, et al. (2011) Acute effects of low doses of ethanol on left and right ventricular function in young healthy subjects. Alcohol Clin Exp Res 35: 1860-1865. 
Albakri A (2018) Alcoholic cardiomyopathy: A review of literature on clinical status and meta-analysis of diagnostic and clinical management methods

54. Regan TJ, Levinson GE, Oldewurtel HA, Frank MJ, Weisse AB, et al. (1969) Ventricular function in noncardiacs with alcoholic fatty liver: role of ethanol in the production of cardiomyopathy. J Clin Invest 48: 397-407. [Crossref]

55. Kupari M, Koskinen P, Suokas A, Ventilä M (1990) Left ventricular filling impairment in asymptomatic chronic alcoholics. Am J Cardiol 66: 1473-1477.

56. Kupari M (1983) Acute cardiovascular effects of ethanol A controlled non-invasive study. Br Heart J 49: 174-182. [Crossref]

57. Regan TJ, Levinson GE, Oldewurtel HA, Frank MJ, Weisse AB, et al. (1969) Ventricular function in noncardiacs with alcoholic fatty liver: role of ethanol in the production of cardiomyopathy. J Clin Investig 48: 397-407.

58. Greenberg BH, Schutz R, Grunkemeier GL, Griswold H (1982) Acute effects of alcohol in patients with congestive heart failure. Ann Intern Med 97: 171-175. [Crossref]

59. Zambrano SS, Mazzotta JF, Sherman D, Spodick DH (1974) Cardiac dysfunction in unselected chronic alcoholic patients: noninvasive screening by systolic time intervals. Am Heart J 87: 318-320.

60. Mathews EC, Gardin JM, Henry WL, Del Negro AA, Fletcher RD, et al. (1981) Echocardiographic abnormalities in chronic alcoholics with and without overt congestive heart failure. Am J Cardiol 47: 570- 578

61. Lazarevic AM, Nakatani S, Neskovic AN, Marinkovic J, Yasumura Y, et al. (2000) Early changes in left ventricular function in chronic asymptomatic alcoholics: relation to the duration of heavy drinking. J Am Coll Cardiol 35: 1599-1606.

62. Urbano Marquez A, Estruch R, Navarro Lopez F, Grau JM, Mont L, et al. (1989) The effects of alcoholism on skeletal and cardiac muscle. $N$ Engl J Med 320: 409-415. [Crossref]

63. Rubin E (1979) Alcoholic myopathy in heart and skeletal muscle. $N$ Engl J Med 301: 28-33. [Crossref]

64. Ferrans VJ, Hibbs RG, Weilbaecher DG, Black WC, Walsh JJ, et al. (1965) Alcoholic cardiomyopathy; a histochemical study. Am Heart J 69:748-765.

65. Chen DB, Wang L, Wang PH (2000) Insulin-like growth factor I retards apoptotic signaling induced by ethanol in cardiomyocytes. Life Sci 67: 1683-1693. [Crossref]

66. Jänkälä H, Eklund KK, Kokkonen JO, Kovanen PT, Linstedt KA, et al. (2001). Ethano infusion increases ANP and $\mathrm{p} 21$ gene expression in isolated perfused rat heart. Biochem Biophys Res Commun 281: 328-333.

67. Danziger RS, Sakai M, Capogrossi MC, Spurgeon HA, Hansford RG, et al. (1991) Ethanol acutely and reversibly suppresses excitation-contraction coupling in cardiac myocytes. Circ Res 68: 1660-1668.

68. Thomas AP, Sass EJ, Tun Kirchmann TT, Rubin E (1989) Ethanol inhibits electricallyinduced calcium transients in isolated rat cardiac myocytes. $J$ Mol Cell Cardiol 21: 555-565.

69. Siddiq T, Salisbury JR, Richardson PJ, Preedy VR (1993) Synthesis of ventricular mitochondrial proteins in vivo: effect of acute ethanol toxicity. Alcohol Clin Exp Res 17: 894-899.

70. Paradis V, Kollinger M, Fabre M, Holstege A, Poynard T, et al. (1997) In situ detection of lipid peroxidation by-products in chronic liver diseases. Hepatology 26: 135-142. [Crossref]

71. Ho E, Karimi GK, Liu CC, Bhindi R, Figtree GA (2013) Biological markers of oxidative stress: Applications to cardiovascular research and practice. Redox Biology 1: 483-491.

72. Capasso JM, Li P, Guideri G, Malhotra A, Cortese R, Anversa P (1992) Myocardial mechanical, biochemical, and structural alterations induced by chronic ethanol ingestion in rats. Circulation Research 71: 346-356.

73. Zhang RH, Gao JY, Guo HT, Scott GI, Eason AR, et al. (2013) Inhibition of CYP2E1 attenuates chronic alcohol intake-induced myocardial contractile dysfunction and apoptosis. Biochimica et Biophysica Acta 1832: 128-241.

74. Segel LD, Rendig SV, Mason DT (1981) Alcohol-induced cardiac hemodynamic and $\mathrm{Ca} 2+$ flux dysfunctions are reversible. J Mol Cell Cardiol 13: 443-455.

75. Sarma JS, Ikeda S, Fischer R, Maruyama Y, Weishaar R, et al. (1976) Biochemical and contractile properties of heart muscle after prolonged alcohol administration. $J \mathrm{Mol}$ Cell Cardiol 8: 951-972.

76. Bing RJ, Tillmanns H, Fauvel JM, Seeler K, Mao JC (2017) Effect of prolonged alcohol administration on calcium transport in heart muscle of the dog. Circulation Research 35: 33-38.

77. Segel LD, Rendig SV, Choquet Y, Chacko K, Amsterdam EA, et al. (1975) Effects of chronic graded ethanol consumption on the metabolism, ultrastructure, and mechanical function of the rat heart. Cardiovascular Research 9: 649-663.
78. Weishaar R, Sarma JS, Maruyama Y, Fischer R, Bertuglia S, et al. (1977) Reversibility of mitochondrial and contractile changes in the myocardium after cessation of prolonged ethanol intake. Am J Cardiol 40: 556-562.

79. Urbano Marquez A, Estruch R, Navarro-Lopez F, Grau JM, Mont L, et al. (1989) The effects of alcoholism on skeletal and cardiac muscle. N Engl J Med 320: 409-415.

80. Jing L, Jin CM, Li SS, Zhang FM, Yuan L, et al. (2012) Chronic alcohol intakeinduced oxidative stress and apoptosis: role of CYP2E1 and calpain-1 in alcoholic cardiomyopathy. Mol Cell Biochem 359: 283-392.

81. Hu C, Ge F, Hyodo E, Arai K, Iwata S, et al. (2013) Chronic ethanol consumption increases cardiomyocyte fatty acid uptake and decreases ventricular contractile function in C57BL/6J mice. J Mol Cell Cardiol 59: 30-40.

82. Vikhert AM, Tsiplenkova VG, Cherpachenko NM (2017) Alcoholic cardiomyopathy and sudden cardiac death. J Am Coll Cardiol 8: 3-11.

83. Kino M (1981) Chronic effects of ethanol under partial inhibition of catalase activity in the rat heart: light and electron microscopic observations. J Mol Cell Cardiol 13: 5-21.

84. Nadal Ginard B, Kajstura J, Anversa P (2003) A matter of life and death: cardiac myocyte apoptosis and regeneration. J Clin Invs 111: 1457-1459.

85. Farber NB, Olney JW (2003) Drugs of abuse that cause developing neurons to commit suicide. Brain Res Dev Brain Res 147: 37-45.

86. Zámbó V, Simon-Szabó L, Szelényi P, Kereszturi E, Bánhegyi G, et al. (2013) Lipotoxicity in the liver. World J Hepatol 5: 550-557. [Crossref]

87. Hibbs RG, Ferrans VJ, Black WC, Weilbaecher DG, Burch GE (1965) Alcoholic Cardiomyopathy; an Electron Microscopic Study. Am Heart J 69: 66-779.

88. Fernandez Sola J, Fatjo F, Sacanella E, Estruch R, Bosch X, et al. (2006) Evidence of apoptosis in alcoholic cardiomyopathy. Human Pathology 37: 1100-1110.

89. Fernandez Sola J, Lluis M, Sacanella E, Estruch R, Antunez E, et al. (2011) Increased myostatin activity and decreased myocyte proliferation in chronic alcoholic cardiomyopathy. Alcohol Clin Exp Res 35: 1220-1229.

90. Marzetti E, Csiszar A, Dutta D, Balagopal G, Calvani R, et al. (2013) Role of mitochondrial dysfunction and altered autophagy in cardiovascular aging and disease: from mechanisms to therapeutics. Am J Physiol Heart Circ Physiol 305: 459-676.

91. Tsiplenkova VG, Vikhert AM, Cherpachenko NM (1986) Ultrastructural and histochemical observations in human and experimental alcoholic cardiomyopathy. $J$ Am Coll Cardiol 8: 22-32.

92. Lange LG, Sobel BE (1983) Myocardial metabolites of ethanol. Circulation Research 72: 724-731.

93. Beckemeier ME, Bora PS (1998) Fatty acid ethyl esters: potentially toxic products of myocardial ethanol metabolism. J Mol Cell Cardiol 30: 2487-2494.

94. Kaphalia BS, Cai P, Khan MF, Okorodudu AO, Ansari GA (2004) Fatty acid ethyl esters: markers of alcohol abuse and alcoholism. Alcohol 34: 151-158. [Crossref]

95. Gulati A, Ismail TF, Jabbour A, Alpendurada F, Guha K, et al. (2013) The prevalence and prognostic significance of right ventricular systolic dysfunction in non-ischemic dilated cardiomyopathy. Circulation 113: 1-37.

96. Steiner JL, Lang CH (2017) Etiology of alcoholic cardiomyopathy: Mitochondria oxidative stress and apoptosis. Int J Biochem Cell Biol 89: 125-135.

97. Wexler RK, Elton T, Pleister A, Feldman D (2009) Cardiomyopathy: an overview. $A m$ Fam Physician 79: 778-784. [Crossref]

98. Klatsky AL (2004) Alcohol and cardiovascular health. Integr Comp Biol 44: 324-328. [Crossref]

99. Henriksen JH, Miller S (2009) Cardiac and systemic haemodynamic complications of liver cirrhosis. Scand Cardiovasc J 43: 218-225

100. Wexler RK, Elton T, Pleister A, Feldman D (2009) Cardiomyopathy: an overview Am Fam Physician 79: 778-784. [Crossref]

101. Nishimura RA (2003). Hypertrophic Cardiomyopathy: A Patient Perspective. Circulation, 108: 133-135.

102. Ocel JJ, Edwards WD, Tazelaar HD, Petrovic LM, Edwards BS, et al. (2004) Heart and liver disease in 32 patients undergoing biopsy of both organs, with implications for heart or liver transplantation. Mayo Clin Proc 79: 492-501. [Crossref]

103. Wilke A, Hesse H, Kaiser A, Ferency I, Arndt T, et al. (1998) Carbohydrate-deficien transferrin in patients with alcoholic cardiomyopathy. J Clin Bas Cardiol 1: 34-36. 
104. Cohen JA, Kaplan MM (1979) The SGOT/SGPT ratio--an indicator of alcoholic liver disease. Dig Dis Sci 24: 835-838. [Crossref]

105. Williams AL, Hoofnagle JH (1988) Ratio of serum aspartate to alanine aminotransferase in chronic hepatitis. Relationship to cirrhosis. Gastroenterology 95 : 734-739.

106. Salaspuro M (1999) Carbohydrate-deficient transferrin as compared to other markers of alcoholism: a systematic review. Alcohol 19: 261-271. [Crossref]

107. Xiao F, Yuan W, Li X, Wang G, Jiang T, et al. (2014) A case of heart failure due to alcoholic cardiomyopathy combined with acute pulmonary embolism. $J$ Thorac Dis 6: $176-180$.

108. Madhubala V, Subhashree AR, Shanthi B (2013) Serum Carbohydrate Deficient Transferrin as a Sensitive Marker in Diagnosing Alcohol Abuse: A Case - Control Study. J Clin Diagn Res 7: 197-200.

109. Bell H, Tallaksen CC, Haug E, Try K (1996) A Comparison between two Commercial Methods for Determining Carbohydrate Deficient Transferrin (CDT). Alcohol Clin Exp Res 20: 449-454

110. Walter H, Hertling I, Benda N, König B, Ramskogler K, et al. (2001) Sensitivity and Specificity of Carbohydrate- Deficient Transferrin in Drinking Experiments and Different Patients. Alcohol 25: 189-194.

111. Mundle G, Ackermann K, Munkes J, Steinle D, Mann K (2000) Influence of Age, Alcohol Consumption and Abstinence on the Sensitivity of Carbohydrate-Deficient Transferrin, Gamma-Glutamyltransferase and Mean Corpuscular Volume. Alcohol 34: 760-766.

112. Hock B, Schwarz M, Domke I, Grunert VP, Wuertemberger M, et al. (2005) Validity of Carbohydrate- Deficient Transferrin (\%CDT), Gamma-Glutamyltransferase (Gamma-Gt) and Mean Corpuscular Erythrocyte Volume (MCV) as Biomarkers for Chronic Alcohol Abuse: A Study in Patients with Alcohol Dependence and Liver Disorders of Non-Alcoholic and Alcoholic Origin. Addiction 100: 1477-1486.

113. Rublo M, Caballería J, Deulofeu R, Caballería L, Gassó M, et al. (1997) CarbohydrateDeficient Transferrin as a Marker of Alcohol Consumption in Male Patients with Liver Disease. Alcohol Clin Exp Res 21: 923-927.

114. Madhubala V, Subhashree AR, Shanthi B (2013) Serum Carbohydrate Deficient Transferrin as A Sensitive Marker in Diagnosing Alcohol Abuse: A Case - Control Study. J Clin Diagn Res 7: 197-200.

115. Yamada M, Seimiya M, Satoh M, Itoga S, Sogawa K, et al. (2013) Determination of Serum Carbohydrate-Deficient Transferrin (CDT) by the Nephelometric N Latex CDT Assay in Japanese Habitual Drinkers and Patients with Non-Alcoholic Liver Diseases. J Alcoholism Drug Depend, 1:138.
116. Yersin B, Nicolet JF, Dercrey H, Burnier M, van Melle G, et al. (1995) Screening for Excessive Alcohol Drinking. Comparative Value of Carbohydrate- Deficien Transferrin, Gamma-Glutamyltransferase, and Mean Corpuscular Volume. Arch Intern Med 155: 1907-1911.

117. Aithal AG, Thornes H, Dwarakanath AD, Tanner AR (1998) Measurement of Carbohydrate-Deficient Transferrin (CDT) in a General Medical Clinic: Is This Test Useful in Assessing Alcohol Consumption. Alcohol Alcohol 33: 304-309.

118. Allen JP, Litten RZ, Fertig JB, Sillanaukee P (2000) Carbohydrate-Deficient Transferrin, Gamma-Glutamyltransferase, and Macrocytic Volume as Biomarkers of Alcohol Problems in Women. Alcohol Clin Exp Res 24: 492-496.

119. Burch GE, Giles TD (1971) Alcoholic cardiomyopathy. Concept of the disease and its treatment. Am J Med 50: 141-145. [Crossref]

120. McDonald CD, Burch GE, Walsh JJ (1971) Alcoholic cardiomyopathy managed with prolonged bed rest. Ann Intern Med 74: 681-691. [Crossref]

121. Moss AJ, Zareba W, Hall WJ (2002). Prophylactic implantation of a defibrillator in patients with myocardial infarction and reduced ejection fraction. N Engl J Med 346: 877-883.

122. George A, Figueredo VM (2010) Alcohol and arrhythmias: a comprehensive review. J Cardiovasc Med (Hagerstown) 11: 221-228. [Crossref]

123. La Vecchia L, Bedogni F, Bozzola L, Bevilacqua P, Ometto R, et al. (1996) Predication of recovery after abstinence in alcoholic cardiomyopathy: role of hemodynamic and morphometric parameters. Clin Cardiol 19: 45-50.

124. Nicolás JM, Fernández Solà J, Estruch R, Paré JC, Sacanella E, et al. (2002) The Effect of Controlled Drinking in Alcoholic Cardiomyopathy. Ann Intern Med 136 192-200.

125. Fauchier L, Babuty D, Poret P, Casset Senon D, Autret ML, et al. (2000) Comparison of long-term outcome of alcoholic and idiopathic dilated cardiomyopathy. Eur Heart J21: 306-314.

126. Duncker D, König T, Hohmann S, Bauersachs J, Veltmann C (2017) Ventricular arrhythmias in patients with newly diagnosed nonischemic cardiomyopathy: Insights from the PROLONG study. Clinical Cardiology 40: 586-590.

127. Guzzo Merello G, Segovia J, Dominguez F, Cobo Marcos M, Gomez Bueno M, et al (2015) Natural History and Prognostic Factors in Alcoholic Cardiomyopathy. JACC Heart Failure 3: 78-86.

128. McDonald CD, Burch GE, Walsh JJ (1971) Alcoholic cardiomyopathy managed with prolonged bed rest. Ann Intern Med 74: 681-691. [Crossref]

Copyright: $(02018$ Albakri A. This is an open-access article distributed under the terms of the Creative Commons Attribution License, which permits unrestricted use, distribution, and reproduction in any medium, provided the original author and source are credited. 